\author{
Universidade de São Paulo \\ Faculdade de Medicina de Ribeirão Preto \\ Departamento de Fisiologia
}

\title{
PARTICIPAÇÃO DO FATOR LIBERADOR DE CORTICOTROFINA NOS EFEITOS DO ESTRADIOL NO CONTROLE DA HOMEOSTASE ENERGÉTICA
}

Paula Beatriz Marangon

Ribeirão Preto - SP

2011 


\section{PARTICIPAÇÃO DO FATOR LIBERADOR DE CORTICOTROFINA NOS EFEITOS DO ESTRADIOL NO CONTROLE DA HOMEOSTASE ENERGÉTICA}

Dissertação apresentada à Faculdade de Medicina de Ribeirão Preto da Universidade de São Paulo, como requisito parcial à obtenção do título de Mestre em Ciências.

Área de concentração: Fisiologia

Orientadora: Profa ${ }^{\mathrm{D}}{ }^{\mathrm{a}}$ Lucila Leico K. Elias

Ribeirão Preto 


\title{
PARTICIPAÇÃO DO FATOR LIBERADOR DE CORTICOTROFINA NOS EFEITOS DO ESTRADIOL NO CONTROLE DA HOMEOSTASE ENERGÉTICA
}

\author{
Dissertação apresentada à Faculdade de \\ Medicina de Ribeirão Preto da Universidade de \\ São Paulo, como requisito parcial à obtenção \\ do título de Mestre em Ciências.
}

Área de concentração: Fisiologia

BANCA EXAMINADORA

Prof. (a) Dr. (a) Instituição: Assinatura:

Prof. (a) Dr. (a) Instituição: Assinatura:

Prof. (a) Dr. (a) Instituição: Assinatura:

Ribeirão Preto, de de 2011 
RESUMO 
MARANGON, P.B. PARTICIPAÇÃO DO FATOR LIBERADOR DE CORTICOTROFINA NOS EFEITOS DO ESTRADIOL NO CONTROLE DA HOMEOSTASE ENERGÉTICA. Faculdade de Medicina de Ribeirão Preto, Universidade de São Paulo, Ribeirão Preto, 2011.

A homeostase energética é controlada por fatores neurais, endócrinos, adipocitários e intestinais. O sistema nervoso central (SNC) recebe sinalização de fatores periféricos e exerce uma função fundamental no controle da homeostase energética, estando bem estabelecido que existem populações neuronais que expressam neuropeptídeos que medeiam efeitos específicos na ingestão e/ou gasto energético. $\mathrm{O}$ fator liberador de corticotrofina (CRF), além de seus efeitos no controle da atividade do eixo hipotálamo-hipófise-adrenal, tem sido descrito como potente neuropeptídeo anorexígeno, modulando a ingestão alimentar e o gasto energético. Foi observado que a síntese de CRF é influenciada pela leptina, que atuaria aumentando a ativação de neurônios produtores de CRF no núcleo paraventricular $(\mathrm{PVN})$.

Os hormônios gonadais também participam na regulação da ingestão alimentar, do peso e da composição corporal. O efeito anorexígeno do estradiol é mediado pela ativação de receptores presentes nas áreas envolvidas no controle da homeostase energética. Em trabalho prévio de nosso laboratório foi observado que o menor ganho de peso e ingestão alimentar com o tratamento com estradiol em ratas ovariectomizadas está associado à maior expressão de RNAm de CRF no PVN. Dessa forma, este trabalho visa esclarecer a participação do CRF nos efeitos do estradiol no controle da homeostase energética. Para tanto, foram utilizadas ratas Wistar adultas, pesando entre $200-230 \mathrm{~g}$, provenientes do Biotério Central do Campus de Ribeirão Preto - USP. Todos os animais foram submetidos à cirurgia de 
ovariectomia bilateral. Em todos os experimentos, houve três grupos de animais: ratas ovariectomizadas $(\mathrm{OVX})$, ratas ovariectomizadas com reposição de estradiol $(\mathrm{OVX}+\mathrm{E})$ e ratas ovariectomizadas com dieta pareada ao grupo $\mathrm{OVX}+\mathrm{E}(\mathrm{OVX}+\mathrm{DP})$. Durante os oitos dias de cada experimento, estes animais receberam injeção subcutânea de cipionato de estradiol (10 $\mu \mathrm{g} / \mathrm{Kg}$ peso corporal, Grupo OVX+E) ou veículo (óleo de milho: 0,2 mL/rata, Grupos OVX e OVX+DP) entre 8h e 10h. Para avaliarmos a participação do CRF nos efeitos da leptina nos animais castrados com e sem reposição de estradiol, foi realizado o tratamento com injeção central de leptina $(10 \mu \mathrm{g} / 5 \mu \mathrm{L})$ com e sem injeção central prévia de antagonista de CRF (antisauvagina-30). Observamos que o tratamento com cipionato de estradiol causa a redução na ingestão alimentar e no ganho de peso corporal. Ainda, quando realizamos a administração central de leptina há anorexia, perda de peso corporal, aumento na expressão de UCP-1 no BAT e na ativação neuronal no ARQ. Esses efeitos são revertidos quando realizamos administração central prévia do antagonista de CRF-R2. Os dados obtidos sugerem que o estradiol aumenta a sensibilidade à leptina, sendo este efeito mediado, pelo menos em parte, pelo receptor tipo 2 do CRF.

Palavras-chaves: estradiol, fator liberador de corticotrofina, leptina, homeostase energética, tecido adiposo marrom. 
ABSTRACT 
MARANGON, P.B. THE ROLE OF CORTICOTROPIN-RELEASING FACTOR ON ESTRADIOL EFFECTS ON REGULATION OF ENERGY HOMEOSTASIS. School of Medicine of Ribeirao Preto, University of Sao Paulo, Ribeirao Preto, 2011.

Energy homeostasis is controlled by neural, endocrine, adipocyte and gut factors. Central nervous system plays a key role in the control of energy homeostasis; it receives signals from peripheral factors and it is well established that the hypothalamus contains neuronal populations that express important neuropeptides to the control of food intake and energy expenditure. Besides its action in the control of hypothalamus-pituitary-adrenal axis, corticotropin releasing factor (CRF), has been described as an anorexigenic neuropeptide, modulating food intake and energy expenditure. It was shown that CRF synthesis is influenced by leptin, which would act increasing CRF neuron activation in the paraventricular nucleus (PVN). Gonadal hormones also participate in the regulation of food intake, body weight and body composition. Estradiol anorexigenic effect is mediated by specific receptors located in areas involved in the control of energy homeostasis.

It was previously demonstrated that the reduction of food intake and body weight gain in ovariectomized treated rats is associated with an increase in CRF mRNA expression in the PVN. The present study aimed to investigate the role of CRF on estradiol regulation of energy homeostasis. Wistar female rats, weighing 200 - 230g, were bilaterally ovariectomized and divided into three groups: ovariectomized rats $(\mathrm{OVX})$, ovariectomized rats treated with estradiol $(\mathrm{OVX}+\mathrm{E})$ and ovariectomized rats pair-fed with $\mathrm{OVX}+\mathrm{E}$ rats $(\mathrm{OVX}+\mathrm{PF})$. The animals received daily subcutaneous injections of either estradiol cypionate $(10 \mu \mathrm{g} / \mathrm{Kg}$ bw, OVX+E) or vehicle (corn oil, OVX, OVX+PF) between $8-10$ am, during 8 days. To evaluate the role of CRF on leptin's effects we performed intracerebroventricular (icv) injection of 
recombinant leptin $(10 \mu \mathrm{g} / 5 \mu \mathrm{L})$ with or without previous icv treatment with CRF-R2 antagonist (ansauvagin-30). We observed that estradiol replacement in OVX rats induced lower food intake and body weight gain. Leptin icv treatment reduced food intake, body weight gain and increased UCP-1 expression in brown adipose tissue and neuronal activation in the arcuate nucleus. These effects were abolished with previous icv administration of CRF-R2 antagonist. In conclusion, our data suggest that estradiol increases central sensitivity to leptin and this effect is mediated, at least in part, by CRF type 2 receptor.

Key words: estradiol, corticotropin releasing-factor, leptin, energy homeostasis, brown adipose tissue. 


\section{LISTA DE ILUSTRAÇÕES}

Figura 1. Efeito do tratamento com cipionato de estradiol sobre a ingestão alimentar diária $(A)$ e acumulada $(B) . \quad N=15-20$. Valores expressos como média \pm EPM. ${ }^{*} p<0,05$ comparado ao grupo OVX

Figura 2. Efeito do tratamento com cipionato de estradiol sobre o ganho de peso corporal diário $(A)$ e total $(B) . \quad \quad N=20$. Valores expressos como média \pm EPM. ${ }^{*} p<0,05 e^{* * *} p<0,001$ comparado ao grupo OVX

Figura 3. Efeito do tratamento com cipionato de estradiol sobre a ingestão alimentar diurna $(A)$ e noturna $(B) . \quad \quad N=6-7$. Valores expressos como média \pm EPM. ${ }^{* * *} p<0,001$ comparado ao grupo OVX 48

Figura 4. Efeito do tratamento com cipionato de estradiol sobre a ingestão de água acumulada. $N=6-7$. Valores expressos como média \pm EPM. Não foi observada diferença estatística significativa entre os grupos .48

Figura 5. Efeito do tratamento com cipionato de estradiol sobre o peso relativo do tecido adiposo marrom $(n=20)$. Valores expressos como média \pm EPM. Não foi observada diferença estatística significativa entre os grupos .49

Figura 6. Efeito do tratamento com cipionato de estradiol sobre as concentrações plasmáticas de corticosterona e leptina $(n=6-11)$. Valores expressos como média \pm EPM. ${ }^{*} p<0,05$ 
Figura 7. Efeito do pré-tratamento com antagonista de CRF-R2 (ASG) no ganho de peso corporal (A) e na ingestão alimentar (B) após estímulo com leptina em ratas tratadas com estradiol $(n=6-7)$. Valores expressos como média + EPM. *: $p<0,001$ vs respectivo controle, $\#$ : $p<0,05$ vs salina/leptina .52

Figura 8. Efeito do tratamento com cipionato de estradiol sobre a expressão protéica de UCP-1 $(n=5)$. Valores expressos como média \pm EPM. ${ }^{*} p<0,05$ comparado ao grupo OVX 53

Figura 9. Efeito do pré-tratamento com antagonista de CRF-R2 (ASG) no ganho de peso corporal e na ingestão alimentar após estímulo com leptina em ratas castradas com $(\mathrm{OVX}+\mathrm{E})$ e sem reposição com cipionato de estradiol (OVX; OVX+DP) $(n=5)$. Valores expressos como média + EPM. * : $p<0,05$ vs salina/salina, \# : $p<0,05$ vs salina/Leptina .54

Figura 10. Efeito do pré-tratamento com antagonista de CRF-R2 (ASG) na imunorreatividade para Fos (A) e na imunolocalização de Fos e CART (B) após estímulo com leptina em neurônios do núcleo arqueado de ratas castradas com (OVX+E) e sem reposição com cipionato de estradiol (OVX; OVX+DP) (n=3-5). Valores expressos como média \pm EPM. * : $p<0,05$ vs salina/salina, \# : $p<0,05$ vs salina/Leptina; $\S: p<0,05$ vs OVX salina/Leptina .56

Figura 11. Fotomicrografias representativas do efeito do pré-tratamento com antagonista de CRF-R2 na imunolocalização de Fos e CART no ARQ após 
estímulo com leptina em ratas castradas com e sem reposição hormonal. Aumento de 40X e 100X 


\section{LISTA DE SIGLAS}

a-CRF: a-helical CRH 8-41

a-MSH: Hormônio estimulador do alfa-melanócito

ACTH: Hormônio adrenocorticotrófico

AgRP: Proteína relacionada ao agouti

ARQ: Núcleo arqueado

ASG: Antisauvagina

AVP: Vasopressina

BAT: Tecido adiposo marrom

CART: Transcrito regulado por cocaína e anfetamina

CCK: Colecistocinina

CRF: Fator liberador de corticotrofina

CRF-R2: Receptor de CRF tipo 2

DMH: Núcleo hipotalâmico dorsomedial

DMV: Núcleo dorsal motor do vago

ERa: Receptor de estrógeno do tipo alfa

ERß: Receptor de estrógeno do tipo beta

IBAT: Tecido adiposo marrom interescapular

icv: Intracerebroventricular

LHA: Área hipotalâmica lateral

MC4R: Receptor 4 da melanocortina

MCH: Hormônio concentrador de melanina

MPOA: Área pré-óptica medial

NPY: Neuropeptídeo Y 
NTS: Núcleo do trato solitário

ObRb: Receptor de forma longa da leptina

OT: Ocitocina

OVX: Ovariectomia

OVX+DP: Ovariectomia com dieta pareada ao grupo OVX+E

OVX+E: Ovariectomia com reposição de estradiol

POMC: Pró-opiomelanocortina

PRL: Prolactina

PVN: Núcleo paraventricular

RCA: Área retroquiasmática

sc: Subcutâneo

SCN: Núcleo supraquiasmático

SNA: Sistema nervoso autônomo

SNC: Sistema nervoso central

SNS: Sistema nervoso simpático

SON: Núcleo supraóptico

TRH: Hormônio liberador de tireotrofina

UCP-1: Proteína desacopladora do tipo 1

VMH: Núcleo hipotalâmico ventromedial 


\section{ÍNDICE}

1. INTRODUÇÃO

2. OBJETIVOS

3. MATERIAIS E MÉTODOS 30

3.1. Animais 31

3.2. Protocolos Experimentais 31

3.3. Procedimentos Cirúrgicos 37

3.4. Coleta de Sangue .39

3.5. Perfusão cerebral. 39

3.6. Métodos Laboratoriais .40

3.7. Análise Estatística. .44

\section{RESULTADOS}

4.1. Avaliação da ingestão alimentar e do peso corporal em ratas ovariectomizadas com e sem reposição de estradiol .46

4.2. Avaliação das concentrações plasmáticas de corticosterona e leptina em ratas ovariectomizadas com e sem reposição de estradiol .50

4.3. Avaliação dos efeitos do antagonista de CRF sobre a ingestão alimentar e o peso corporal após administração central de leptina em ratas ovariectomizadas com e sem reposição de estradiol .51 
4.4. Avaliação dos efeitos do antagonista de CRF sobre a expressão protéica de UCP1 no tecido adiposo marrom após administração central de leptina em ratas ovariectomizadas com e sem reposição de estradiol 53 4.5. Avaliação dos efeitos do antagonista de CRF sobre a expressão de proteína Fos e CART no núcleo arqueado após administração central de leptina em ratas ovariectomizadas com e sem reposição de estradiol

5. DISCUSSÃO .58

6. SUMÁRIO E CONCLUSÕES .71

7. REFERÊNCIAS 73 
1. INTRODUÇÃO 
Nos últimos anos vários estudos têm sido realizados com o intuito de investigar os mecanismos de regulação e as vias neuroendócrinas envolvidas no controle do balanço energético. A compreensão dos processos que regulam a ingestão alimentar e o peso corporal tem contribuído não somente para o melhor conhecimento dos mecanismos fisiológicos envolvidos nestes processos, mas também na elucidação de fatores envolvidos em algumas condições fisiopatológicas como a obesidade e a caquexia.

A obesidade é caracterizada pelo acúmulo excessivo de gordura corporal e representa fator de risco para o desenvolvimento de outras patologias como diabetes mellitus tipo 2, hipercolesterolemia, hipertensão arterial, doenças cardiovasculares, apnéia do sono, doenças ortopédicas e diversos tipos de cânceres (Abrantes e cols, 2002; WHO, 2004). A incidência da obesidade vem aumentando em proporções epidêmicas tanto em países desenvolvidos como em países em desenvolvimento (WHO, 2004). No Brasil, 40\% das pessoas estão com excesso de peso e, estima-se que nos próximos vinte anos, esse número alcançará aproximadamente 60\% (Mancini \& Halpern, 2002; Peixoto et al., 2007).

A causa mais comum de obesidade humana decorre de hábitos alimentares pouco equilibrados, com o consumo elevado de gorduras e açúcares, e hábitos de vida sedentários (Hermanussen et al., 2006), porém causas monogênicas podem também estar associadas ao desenvolvimento da obesidade, como mutações nos genes da leptina, do receptor da leptina, da pró-opiomelanocortina (POMC) ou do receptor da melanocortina-4 (Levin, 2010).

Atualmente, sabe-se que a ingestão e o peso corporal são controlados por importantes fatores neurais, endócrinos, adipocitários e intestinais, cuja integração contribui para a homeostase energética (Schwartz e cols, 2000). Para a 
manutenção do balanço energético e do peso corporal é necessário um equilíbrio entre a ingestão de macronutrientes e o gasto energético. Assim, um balanço energético positivo resulta em ganho de peso, ao passo que um balanço energético negativo resulta em perda de peso. O sistema nervoso central (SNC), juntamente com uma série de sinais periféricos indicadores do estado nutricional exerce uma função fundamental na manutenção da homeostase energética. O hipotálamo foi a primeira região descrita neste processo homeostático há mais de cinqüenta anos (Stellar, 1954). Na década de quarenta, lesões e estímulos elétricos de núcleos hipotalâmicos, inicialmente, sugeriram que o núcleo hipotalâmico ventromedial (VMH) representava o "centro da saciedade" e a área hipotalâmica lateral (LHA) o "centro da fome" (Hetherington \& Ranson, 1940; Anand \& Brobeck, 1951; Stellar, 1954). Lesões bilaterais no VMH resultavam em hiperfagia e obesidade, por outro lado, lesões na LHA induziam anorexia e acentuada perda de peso (Hetherington \& Ranson, 1940; Anand \& Brobeck, 1951; Stellar, 1954). Entretanto, com o avanço dos estudos relacionados ao comportamento alimentar, a visão de "centros" funcionais tem sido substituída por populações neuronais, as quais expressam neuropeptídeos que medeiam efeitos específicos na ingestão e/ou gasto energético (Schwartz e cols, 2000).

Atualmente sabe-se que o hipotálamo contém vários núcleos, além da LHA e do VMH, envolvidos no controle da ingestão alimentar. Dentre eles incluem-se o núcleo arqueado (ARQ), o núcleo paraventricular (PVN) e o núcleo hipotalâmico dorsomedial (DMH) (Stellar, 1954; Bray et al., 1990; Elmquist e cols, 1999). O ARC se situa na base do terceiro ventrículo, acima da eminência mediana, e contém grande número de corpos neuronais, sendo dividido em domínios funcionais. A barreira hematoencefálica nessa região se encontra modificada, permitindo a 
passagem de peptídeos e proteínas, como a insulina e a leptina (Berthoud \& Morrison, 2008; Williams et al., 2000). Alguns hormônios possuem receptores específicos expressos em grupamentos neuronais do $A R Q$ e atuam regulando a ingestão alimentar, como leptina, ghrelina, hormônio do crescimento, glicocorticóides, esteróides sexuais, insulina e metabólitos como a glicose (Berthoud, 2002). O ARC está envolvido nos processos controladores da ingestão alimentar e gasto energético por meio da produção, armazenamento e liberação de peptídeos anorexígenos, biomoléculas inibidoras do apetite, como a proopiomelanocortina (POMC) e o transcrito regulado por cocaína e anfetamina (CART), e orexígenos, biomoléculas estimulantes do apetite, como o neuropeptídeo Y (NPY) e a proteína relacionada ao agouti (AgRP). Sinais periféricos, como a leptina e insulina, modulam a atividade dos neurônios do $A R Q$, que, por sua vez, desencadeiam a ativação de vias neurais hipotalâmicas que coordenam o metabolismo periférico, principalmente por acionar o sistema nervoso autônomo (SNA) e o sistema endócrino (Williams e cols, 2000).

No ARC, existem duas populações neuronais, uma que co-expressa POMC e CART e outra que co-expressa NPY e AgRP. Essas duas populações neuronais mantêm projeções recíprocas e enviam projeções para neurônios de segunda ordem em outras áreas do hipotálamo, relacionadas à ingestão alimentar, como o PVN, a LHA, o DMH e o VMH (Sawchenko, 1998; Schwartz e cols, 2000). O PVN envia projeções descendentes para estruturas autonômicas no tronco encefálico, como o núcleo do trato solitário (NTS) e o núcleo dorsal motor do vago (DMV) (Swanson and Sawchenko, 1983).

Um dos neuropeptídeos que inibe a ingestão alimentar é o CART. Este peptídeo é encontrado em vários núcleos hipotalâmicos como $A R C, P V N, D M H$, 
LHA; e em outras áreas entre as quais eminência mediana, hipófise anterior, pâncreas e medula adrenal (Gautvik e cols, 1996; Couceyro e cols, 1997; Kuhar \& Dall Vechia, 1999, Wierup \& Sundler, 2006). Este neuropeptídeo está co-localizado com a POMC no ARC, como apontado acima, mas também com o hormônio concentrador de melanina $(\mathrm{MCH})$ na LHA e com o hormônio liberador de tireotrofina (TRH), galanina, vasopressina (AVP) e ocitocina (OT) no PVN (Kristensen e cols, 1998; Kuhar \& Dall Vechia, 1999). A administração intracerebroventricular (icv) crônica de CART diminui a ingestão alimentar e o peso corporal tanto em ratos obesos fa/fa como em ratos controles (Larsen et al., 2000). Adicionalmente, ratos Wistar com privação alimentar por 24 ou 48 horas bem como camundongos ob/ob (deficientes em leptina) apresentam redução de RNAm de CART no ARQ (Kristensen e cols, 1998). Ambati e cols., 2007, utilizando ratos Sprague-Dawley demonstraram que a administração icv de leptina é capaz de aumentar a expressão do RNAm para CART no ARQ.

As melanocortinas são peptídeos bioativos derivados da molécula precursora pró-opiomelatocortina produzidos no ARQ, NTS, hipófise, pele e em tecidos periféricos, como os órgãos reprodutores (Mountjoy, 2010). Os produtos derivados da POMC presentes em cada tecido variam de acordo com as endoproteases presentes (Arora, 2006). Na hipófise anterior, a transcrição do gene da POMC é estimulada pelo CRF, resultando na síntese e secreção do hormônio adrenocorticotrófico (ACTH). No hipotálamo, a clivagem da POMC no ARQ resulta na síntese de $\alpha-\mathrm{MSH}$, sendo este neuropeptídeo importante na integração de informações do status energético, a partir de fatores periféricos como insulina e leptina (Cowley et al., 2001). O $\alpha-\mathrm{MSH}$ atua como ligante endógeno do receptor 4 da melanocotina (MC4R), molécula chave na regulação do controle do apetite e da 
homeostase energética. Além disso, o AgRP foi descrito como antagonista endógeno desse receptor, havendo uma regulação dinâmica desse sistema in vivo (Arora, 2006).

O fator liberador de corticotrofina (CRF), além de sua função clássica na regulação do eixo hipotálamo-hipófise-adrenal, tem sido descrito como potente anorexígeno (Rohner Jeanrenaud et al., 1989; Heinrichs et al., 1996). A administração icv de CRF está associada com a redução da ingestão alimentar e do peso corporal (Morley \& Levine, 1982; Arase et al., 1988). Além de alterar o balanço energético por meio de seus efeitos na ingestão alimentar, o CRF também interfere no gasto energético, uma vez que é capaz de agir no SNC e regular a atividade do SNA, aumentando a atividade simpática e diminuindo a atividade parassimpática (Brown \& Fisher, 1985). O CRF atua por meio de sua ligação a dois receptores distintos, tipos 1 e 2, sendo o último o principal envolvido na supressão da ingestão e na resposta termogênica do CRF (Martinez et al., 1998). Por meio da técnica de hibridização in situ, demonstrou-se que esse receptor se encontra abundantemente expresso no PVN e no VMH (Chalmers et al., 1995). O CRF também é sensível à ação de peptídeos periféricos que sinalizam ao cérebro sobre as flutuações das reservas energéticas do organismo, como a leptina. Foi descrito que a leptina aumenta a expressão de CRF-R2 no VMH (Arora, 2006; Huang et al., 1998).

Os hormônios gonadais também participam na regulação da ingestão alimentar, do peso e da composição corporal de várias espécies de mamíferos. Os estrógenos regulam diversas funções fisiológicas e comportamentais em fêmeas adultas, resultando no aumento do sucesso reprodutivo, sendo uma dessas funções a inibição do apetite (Geary et al., 2001). A deficiência dos hormônios ovarianos pela ovariectomia, por exemplo, leva ao ganho de peso (Wade \& Zucker, 1970; 
Mook et al., 1972; Landau \& Zucker, 1976) e ao aumento do conteúdo de lipídios da carcaça de ratas (Leshner et al., 1973; Gray et al., 1981). Este ganho de peso é acompanhado por uma elevação na ingestão alimentar (Wade, 1970; Mook et al., 1972; Tarttelin, 1973; Landau et al., 1976) e diminuição na atividade locomotora (Mook et al., 1972; Wade, 1975).

Observa-se na maioria das fêmeas de mamíferos como ratas, camundongas, porcas, primatas não-humanos e mulheres, que a ingestão alimentar diminui durante a fase peri-ovulatória e aumenta na fase pós-ovulatória (Wade, 1972; Blaustein \& Wade, 1976; Kemmitz et al., 1989; Dye \& Blundell, 1997; Eckel et al., 2000). Alguns estudos sugerem que esta diminuição no consumo alimentar está relacionada à ação anorexígena do estradiol. Desde a década de 70, Wade e Zucker já relatavam que a administração de benzoato de estradiol em ratas ovariectomizadas promovia redução na ingestão alimentar. Posteriormente, com a descoberta dos receptores de estrógeno ER $\alpha$ e ER $\beta$ (Green et al., 1985; Kuiper et al., 1996), vários pesquisadores concluíram que o efeito anorexígeno do estradiol é mediado pela ativação destes receptores presentes nas áreas envolvidas no controle da homeostase energética, como PVN, VMH e NTS (Butera et al., 1996; Diano et al., 1998; Eckel \& Geary, 2001; Eckel et al., 2002). Shughrue e cols, 1997, utilizando a técnica de hibridização in situ mapearam a distribuição dos dois subtipos de receptores estrogênicos e verificaram maior expressão de ERa no ARQ. Também foi demonstrado que camundongos knockout para o subtipo a do receptor de estrógenos apresentam aumento na ingestão alimentar (Geary et al., 2001). O efeito anorexígeno dos estrógenos aparentemente ocorre através da modulação da expressão do RNAm para POMC, NPY e CRF. Aproximadamente $40 \%$ dos neurônios CRF no PVN expressam ERa, dessa forma, acredita-se que os efeitos 
estrogênicos sobre neurônios CRF sejam diretos (Pelletier et al., 2007). Além disso, observou-se que há co-localização de ERa e leptina no DMH e MPOA e de ERß e leptina no ARQ, MPOA e DMH (Del Bianco-Borges et al., 2010).

A leptina é um hormônio protéico, codificado pelo gene ob em camundongos, e produzida, predominantemente, pelos adipócitos (Zhang et al., 1994), mas pode ser produzida por outros tipos celulares localizados em outros tecidos como placenta (Masuzaki et al., 1997), epitélio gástrico (Bado et al., 1998), músculo esquelético (Wang et al., 1998), células do folículo capilar (Iguchi et al., 2001) e osteoblastos (Reseland et al., 2001). Sua liberação na circulação sangüínea ocorre em proporção à quantidade de tecido adiposo branco. Indivíduos obesos, por exemplo, possuem maior concentração plasmática de leptina quando comparados a indivíduos eutróficos (Maffei et al., 1995; Frederich et al., 1995; Considine et al., 1996).

A síntese e a liberação da leptina pelo tecido adiposo são influenciadas pelo estado alimentar, ou seja, em condições de jejum há uma redução acentuada na expressão de RNAm de leptina no tecido adiposo branco e na sua concentração plasmática (Becker et al., 1995; Trayhurn et al., 1995; Hardie et al., 1996). Contudo, essas mudanças são revertidas com a realimentação (Becker et al., 1995; Trayhurn et al., 1995; Hardie et al., 1996). A administração exógena de leptina resulta em redução do consumo alimentar e da adiposidade, perda de peso e aumento do gasto energético em camundongos ob/ob (Campfield et al., 1995; Pelleymounter et al., 1995; Haynes et al., 1997). Portanto, a concentração plasmática de leptina representa um sinal de retroalimentação na regulação do peso corporal e do balanço energético. 
A ação da leptina ocorre por meio de sua ligação ao seu receptor específico, o qual é membro da família dos receptores de citocina (White \& Tartaglia, 1996). Existem seis formas variantes do receptor de leptina (ObRa, ObRb, ObRc, ObRd, ObRe, ObRf) (Lee et al., 1996; Chua et al., 1997; Tartaglia et al., 1997). O receptor de forma longa $(\mathrm{ObRb})$ é expresso, abundantemente, no hipotálamo; particularmente nas regiões envolvidas na regulação da homeostase energética, como ARC, DMH e LHA (Elmquist et al., 1998). Mutação no gene codificador do receptor de leptina ( $d b$ para camundongos e fa para ratos) induz hiperfagia, obesidade, hiperlipidemia e resistência ao tratamento com leptina exógena (Lee et al., 1996), confirmando a participação essencial da leptina no controle da ingestão alimentar.

Os neurônios NPY/AgRP são inibidos pela leptina, e ativados em condições de concentrações plasmáticas baixas deste hormônio (Stephens et al., 1995; Schwartz et al., 1996; Hahn et al., 1998; Elias et al., 1999). Contrariamente, a leptina ativa os neurônios POMC/CART (Schwartz et al., 1997; Thornton et al., 1997; Kristensen et al., 1998; Cowley et al., 2001). Os axônios destas populações neuronais, por sua vez, projetam-se para neurônios de segunda ordem localizados no PVN, VMH, DMH e LHA (Sawchenko, 1998; Schwartz et al., 2000). Estes neurônios de segunda ordem, que também expressam receptor de leptina (Hakanson et al., 1998; Fei et al., 1997; Elmquist et al., 1998), por sua vez, projetamse para o NTS e para o DMV, no tronco encefálico; integrando assim um circuito neuronal responsável pela regulação do apetite.

Foi demonstrado que o CRF é capaz de mediar os efeitos da leptina na ingestão alimentar em ratos Sprague-Dawley pré-tratados com D-Phe CRF, antagonista dos receptores tipo 1 e 2 do $\mathrm{CRF}$, seguido do tratamento central com 
leptina. Nesses animais, os efeitos da leptina tanto na ingestão alimentar como no ganho de peso corporal foram atenuados pelo antagonista de CRF (Gardner et al., 1998). Uehara e cols, 1998, também evidenciaram a participação do CRF nos efeitos anorexígenos da leptina. Dados recentes de nosso laboratório (Uchoa et al., 2009; Uchoa et al., 2010), demonstraram que no modelo de adrenalectomia bilateral, a hipofagia está associada a um aumento da expressão de RNAm de CRF no PVN e aumento na ativação de neurônios produtores de CRF neste núcleo. Ainda, demonstrou-se que a administração de antagonista de CRF-R2 reverte a hipofagia em animais adrenalectomizados, confirmando a participação importante do CRF na hipofagia neste modelo experimental.

A leptina aumenta o gasto energético por meio de ativação do sistema nervoso autônomo simpático (SNS) que inerva o tecido adiposo marrom (GómezAmbrosi et al., 1999). Até os últimos anos, acreditava-se que este tecido termogênico (Smith, 1961) encontrava-se presente apenas em pequenos mamíferos e em recém-nascidos de grandes mamíferos (Lean, 1989; Sell et al., 2004), porém pesquisas recentes identificaram a presença de tecido adiposo marrom funcional em adultos, mais frequentemente nas mulheres do que nos homens (Cypess et al., 2009). Além disso, estudos demonstram haver uma relação indireta entre a quantidade de tecido adiposo marrom funcionalmente ativa e a presença de sobrepeso ou obesidade (van Marken et al., 2009; Lee et al., 2010; Nedergaard \& Cannon, 2010; Tan et al., 2010).

O tecido adiposo marrom é rico em mitocôndrias caracterizadas por membranas internas bem desenvolvidas (Ricquier \& Bouillaud, 2000), onde está presente a proteína UCP-1 (uncoupling protein 1), específica desse tecido. A expressão da UCP-1 é uma importante indicadora de termogênese nesse tecido, 
pois esta proteína é responsável pela geração de calor através do desacoplamento da entrada de prótons na síntese de ATP (Nicholls et al., 1984). A deficiência de UCP-1, em camundongos, gera uma perda da habilidade de produzir calor e uma intolerância grave ao frio (Enerback et al., 1997). O SNS inerva o tecido adiposo marrom e, por meio da liberação de noradrenalina, ativa receptores $\beta$-adrenérgicos presentes nos adipócitos, estimulando a termogênese, aumentando a expressão da proteína UCP-1, ativação da mitocondriogênese e proliferação de adipócitos (Henrike, 2004).

Os estrógenos exercem seus efeitos catabólicos por meio da modulação da sensibilidade central à leptina. Assim, fêmeas possuem maior sensibilidade central à leptina e maior acúmulo de tecido adiposo subcutâneo (Clegg et al., 2006). Ainda, o 17ß-estradiol é capaz de regular as concentrações plasmáticas de leptina, além de regular a expressão de ObRb no músculo esquelético e tecido adiposo (Alonso et al., 2007). Além disso, foi demonstrado que a inibição da atividade estrogênica, através da conjugação a grupos sulfonados, resulta na redução da síntese de leptina pelos adipócitos em camundongas (Khor et al., 2010). Também, verificou-se que existe co-localização de ObRb e ERa no ARQ e que a expressão do RNAm para ObRb no ARQ é modulada por estrógenos, possivelmente via elementos responsivos aos estrógenos no gene para o receptor da leptina, mecanismo através do qual os estrógenos podem aumentar a sensibilidade à leptina (Diano et al., 1998). Assim, quando os níveis de estrógenos se encontram baixos, isto é, em fêmeas ovariectomizadas e machos intactos, a sensibilidade central à leptina encontra-se reduzida. Ao contrário, quando os níveis de estrógenos são elevados, como ocorre em fêmeas intactas, fêmeas 
ovariectomizadas e machos com reposição com estradiol, a sensibilidade à leptina é elevada (Clegg et al., 2006).

Em trabalho prévio de nosso laboratório foi observado que o menor ganho de peso e ingestão alimentar com o tratamento com estradiol em ratas ovariectomizadas está associado à maior expressão de RNAm de CRF no PVN (Silva et al., 2010) e a maior perda de peso após estímulo central com leptina. Por conseguinte, este trabalho visa esclarecer a participação do CRF nos efeitos do estradiol no controle da homeostase energética. 
2. OBJETIVOS 


\subsection{Objetivos gerais}

Avaliar a participação do CRF nos efeitos do estradiol sobre a ingestão alimentar e peso corporal em resposta à estimulação central com leptina.

\subsection{Objetivos específicos}

1. Avaliar o efeito da ovariectomia (OVX) e da reposição com cipionato de estradiol em animais ovariectomizados $(\mathrm{OVX}+\mathrm{E})$ na ingestão alimentar e ganho de peso corporal;

2. Avaliar o efeito do pré-tratamento com antagonista de CRF-R2 sobre a ingestão alimentar e ganho de peso corporal em ratas OVX, OVX+E e OVX+DP estimuladas com leptina;

3. Avaliar o efeito do pré-tratamento com antagonista de CRF-R2 sobre a expressão de UCP-1 no tecido adiposo marrom, e na ativação de neurônios CART no núcleo arqueado em ratas $\mathrm{OVX}, \mathrm{OVX}+\mathrm{E}$ e $\mathrm{OVX}+\mathrm{DP}$ estimuladas com leptina. 
3. MATERIAIS E MÉTODOS 


\subsection{Animais}

Foram utilizadas ratas adultas, da linhagem Wistar, pesando entre 200250g, provenientes do Biotério Central do Campus de Ribeirão Preto - USP. Os animais foram ambientalizados em gaiolas individuais no biotério do Departamento de Fisiologia e aclimatados em temperatura controlada $\left(23 \pm 2^{\circ} \mathrm{C}\right)$, sob regime de luz com ciclo claro-escuro de 12/12 horas (período de luz: 06h às 18h). Os animais tiveram livre acesso à água e ração, exceto nos experimentos em que houve a retirada da dieta. Os procedimentos experimentais foram aprovados pelo Comitê de Ética em Experimentação Animal (CETEA) da Faculdade de Medicina de Ribeirão Preto - USP (115/2009).

\subsection{Protocolos experimentais}

\subsubsection{Avaliação da ingestão alimentar e do peso corporal em ratas} ovariectomizadas com e sem reposição de estradiol

Após três ciclos estrais regulares, as ratas foram submetidas à ovariectomia bilateral e divididas em três grupos:

- Ratas ovariectomizadas (OVX);

- Ratas ovariectomizadas com reposição com estradiol (OVX+E);

- Ratas ovariectomizadas com dieta pareada ao grupo OVX +E (OVX+DP).

No dia seguinte à cirurgia, estes animais receberam injeção subcutânea de cipionato de estradiol (10 $\mu \mathrm{g} / \mathrm{Kg}$ peso corporal, Grupo OVX+E) ou 
veículo (óleo de milho: 0,2 mL/rata, Grupos OVX e OVX + DP) entre $8 \mathrm{~h}$ e $10 \mathrm{~h}$, por oito dias consecutivos. Durante este período, foram verificados, diariamente, entre $8 \mathrm{~h}$ e $10 \mathrm{~h}$, a ingestão alimentar de 24 horas e o ganho de peso corporal. Em todo o período do experimento, as ratas tiveram livre acesso à água e ração disponibilizados individualmente em gaiolas individuais, exceto como especificado abaixo. A quantidade de dieta do grupo OVX+DP foi calculada pela média de dieta ingerida no dia anterior pelo grupo OVX. Para manter a ingestão alimentar no período noturno, a dieta do grupo OVX+DP foi oferecida às 18 horas.

No oitavo dia, a dieta foi retirada às $16 \mathrm{~h}$, e um grupo de ratas OVX, OVX $+E$ e OVX+DP foi decapitado às $17 \mathrm{~h}$ para coleta de sangue. Ao restante dos animais, a dieta foi reapresentada às $18 \mathrm{~h}$, ou seja, no momento em que a luz do biotério apagou-se, sendo estes animais dos grupos OVX, OVX+E e OVX+DP decapitados às $22 \mathrm{~h}$ para coleta de sangue.

O sangue coletado do tronco foi utilizado para dosagem hormonal de corticosterona e leptina. Além disso, o tecido adiposo marrom foi retirado e pesado.

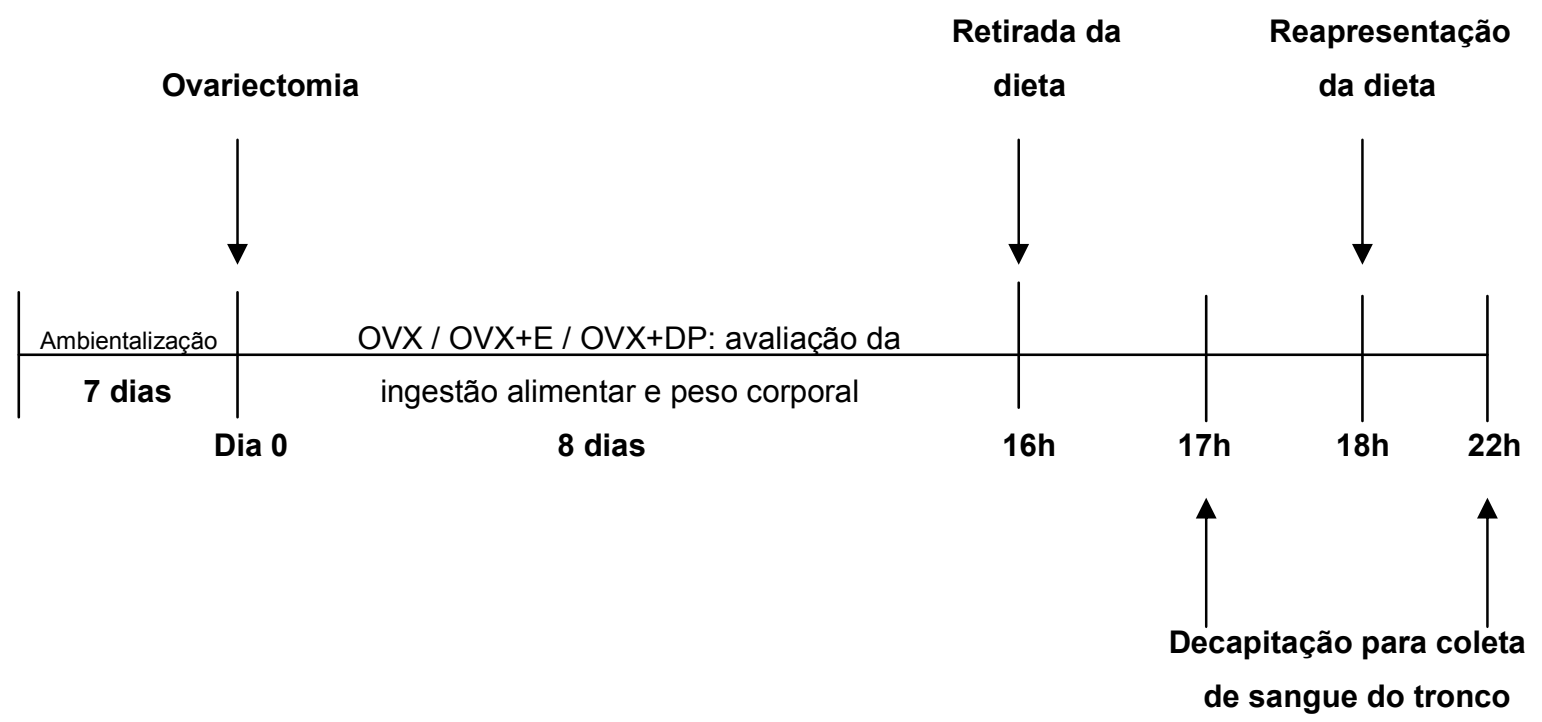


3.2.2. Avaliação dos efeitos do antagonista de CRF sobre a ingestão alimentar e o peso corporal e expressão de UCP-1 no tecido adiposo marrom após administração intracerebroventricular de leptina em ratas ovariectomizadas com e sem reposição de estradiol

Após três ciclos estrais regulares, as ratas foram submetidas à ovariectomia bilateral e à implantação de cânula no ventrículo lateral direito, e logo em seguida divididas nos seguintes grupos:

- Ratas ovariectomizadas (OVX) + veículo + salina;

- Ratas ovariectomizadas (OVX) + antisauvagina 30 + salina;

- Ratas ovariectomizadas (OVX) + veículo + leptina;

- Ratas ovariectomizadas (OVX) + antisauvagina 30 + leptina;

- Ratas ovariectomizadas com reposição com estradiol (OVX + E) + veículo+ salina;

- Ratas ovariectomizadas com reposição com estradiol $(\mathrm{OVX}+\mathrm{E})$ + antisauvagina $30+$ salina;

- Ratas ovariectomizadas com reposição com estradiol $(\mathrm{OVX}+\mathrm{E})$ + veículo + leptina;

- Ratas ovariectomizadas com reposição com estradiol $(\mathrm{OVX}+\mathrm{E})$ + antisauvagina 30 + leptina;

- Ratas ovariectomizadas com dieta pareada ao grupo OVX + E (OVX + DP) + veículo + salina;

- Ratas ovariectomizadas com dieta pareada ao grupo OVX + E (OVX + DP) + antisauvagina 30 + salina; 
- Ratas ovariectomizadas com dieta pareada ao grupo OVX + E (OVX + DP ) + veículo + leptina;

- Ratas ovariectomizadas com dieta pareada ao grupo OVX + E (OVX + DP ) + antisauvagina $30+$ leptina.

No dia seguinte às cirurgias, estes animais receberam injeção subcutânea de cipionato de estradiol (10 $\mu \mathrm{g} / \mathrm{Kg}$ peso corporal, OVX+E) ou veículo (óleo de milho: 0,2 mL/rata, OVX e OVX + DP) entre 8h e 10h, por oito dias consecutivos. Em todo o período do experimento, as ratas tiveram livre acesso à água e ração disponibilizados individualmente em gaiolas individuais, exceto como especificado abaixo.

No oitavo dia, a dieta desses animais foi retirada às $16 \mathrm{~h}$. Às $16: 45 \mathrm{~h}$ os animais receberam injeção icv de antagonista de receptor CRF do tipo 2 (Antisauvagina: $5 \mu \mathrm{g} / 5 \mu \mathrm{L}$, Península/Bachem, EUA) ou veículo ( $\mathrm{NaCl}$ 0,9\%). Após 15 minutos (17h), foi realizada a injeção central de leptina (Leptin, Mouse, Recombinant, E.coli; Calbiochem ${ }^{\circledR}$ ) na dose de $10 \mu \mathrm{g} / 5 \mu \mathrm{L}$ ou veículo (salina estéril: $5 \mu \mathrm{L} /$ rata). Posteriormente, a dieta foi reapresentada às $18 \mathrm{~h}$, ou seja, no momento em que a luz do biotério apagou-se. A avaliação da ingestão alimentar foi realizada 1, 2, 4 e 14 horas após a reapresentação da dieta e o peso corporal foi avaliado 14 horas após. Ao final do experimento, o tecido adiposo marrom foi coletado para posterior extração de proteínas totais e determinação da expressão de UCP-1. 


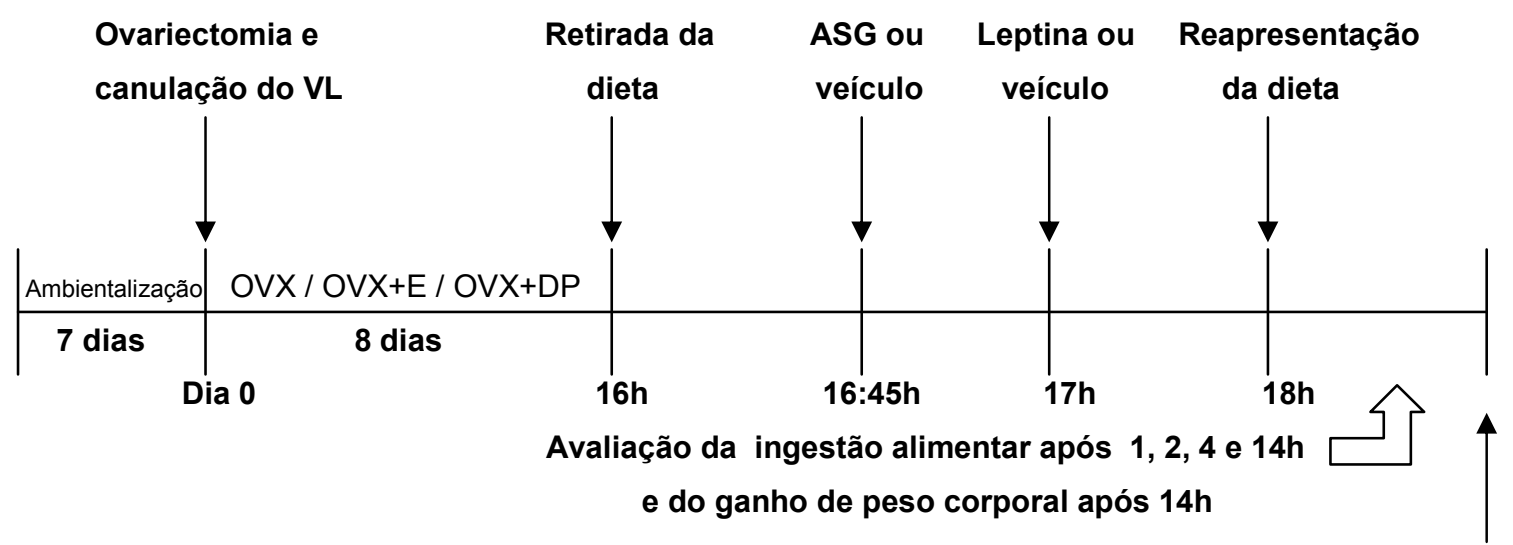

Decapitação e coleta do BAT

3.2.3. Avaliação dos efeitos do antagonista de CRF sobre a expressão de proteína Fos e CART no núcleo arqueado após administração intracerebroventricular de leptina em ratas ovariectomizadas com e sem reposição de estradiol

Após três ciclos estrais regulares, as ratas foram submetidas à ovariectomia bilateral e à implantação de cânula no ventrículo lateral direito, e logo em seguida divididas nos seguintes grupos:

- Ratas ovariectomizadas (OVX) + veículo + salina;

- Ratas ovariectomizadas (OVX) + antisauvagina 30 + salina;

- Ratas ovariectomizadas (OVX) + veículo + leptina;

- Ratas ovariectomizadas (OVX) + antisauvagina 30 + leptina;

- Ratas ovariectomizadas com reposição com estradiol $(\mathrm{OVX}+\mathrm{E})$ + veículo+ salina; 
- Ratas ovariectomizadas com reposição com estradiol $(\mathrm{OVX}+\mathrm{E})+$ antisauvagina $30+$ salina;

- Ratas ovariectomizadas com reposição com estradiol $(\mathrm{OVX}+\mathrm{E})+$ veículo + leptina;

- Ratas ovariectomizadas com reposição com estradiol $(\mathrm{OVX}+\mathrm{E})+$ antisauvagina 30 + leptina;

- Ratas ovariectomizadas com dieta pareada ao grupo OVX + E (OVX + DP) + veículo + salina;

- Ratas ovariectomizadas com dieta pareada ao grupo OVX + E (OVX + DP) + antisauvagina 30 + salina;

- Ratas ovariectomizadas com dieta pareada ao grupo OVX + E (OVX + DP ) + veículo + leptina;

- Ratas ovariectomizadas com dieta pareada ao grupo OVX + E (OVX + DP) + antisauvagina $30+$ leptina.

No dia seguinte às cirurgias, estes animais receberam injeção subcutânea de cipionato de estradiol (10 $\mu \mathrm{g} / \mathrm{Kg}$ peso corporal, $\mathrm{OVX}+\mathrm{E})$ ou veículo (óleo de milho: 0,2 mL/rata, OVX e OVX + DP) entre 8h e 10h, por oito dias consecutivos. Em todo o período do experimento, as ratas tiveram livre acesso à água e ração disponibilizados individualmente em gaiolas individuais, exceto como especificado abaixo. A quantidade de dieta do grupo OVX+DP foi calculada pela média de dieta ingerida pelo grupo OVX. Para manter a ingestão alimentar no período noturno, a dieta do grupo OVX+DP foi oferecida às 18 horas.

No oitavo dia, a dieta desses animais foi retirada às $15 \mathrm{~h}$. Às $16: 15 \mathrm{~h}$ os animais receberam injeção icv de antagonista de receptor CRF do tipo 2 
(Antisauvagina 30: $5 \mu \mathrm{g} / 5 \mu \mathrm{L}$, Península/Bachem, EUA) ou veículo ( $\mathrm{NaCl} 0,9 \%$ ). Após 15 minutos (16:30h), foi realizada a injeção central de leptina (Leptin, Mouse, Recombinant, E.coli; Calbiochem ${ }^{\circledR}$ ) na dose de $10 \mu \mathrm{g} / 5 \mu \mathrm{L}$ ou veículo (salina estéril: $5 \mu \mathrm{L} / \mathrm{rata})$.

Após 90 minutos à administração de leptina ou salina (18h) os animais foram anestesiados com tribromoetanol 2,5\% (1mL/100g de peso corporal) e perfundidos para coleta de tecido cerebral e tronco encefálico para posterior procedimento de imunoistoquímica.

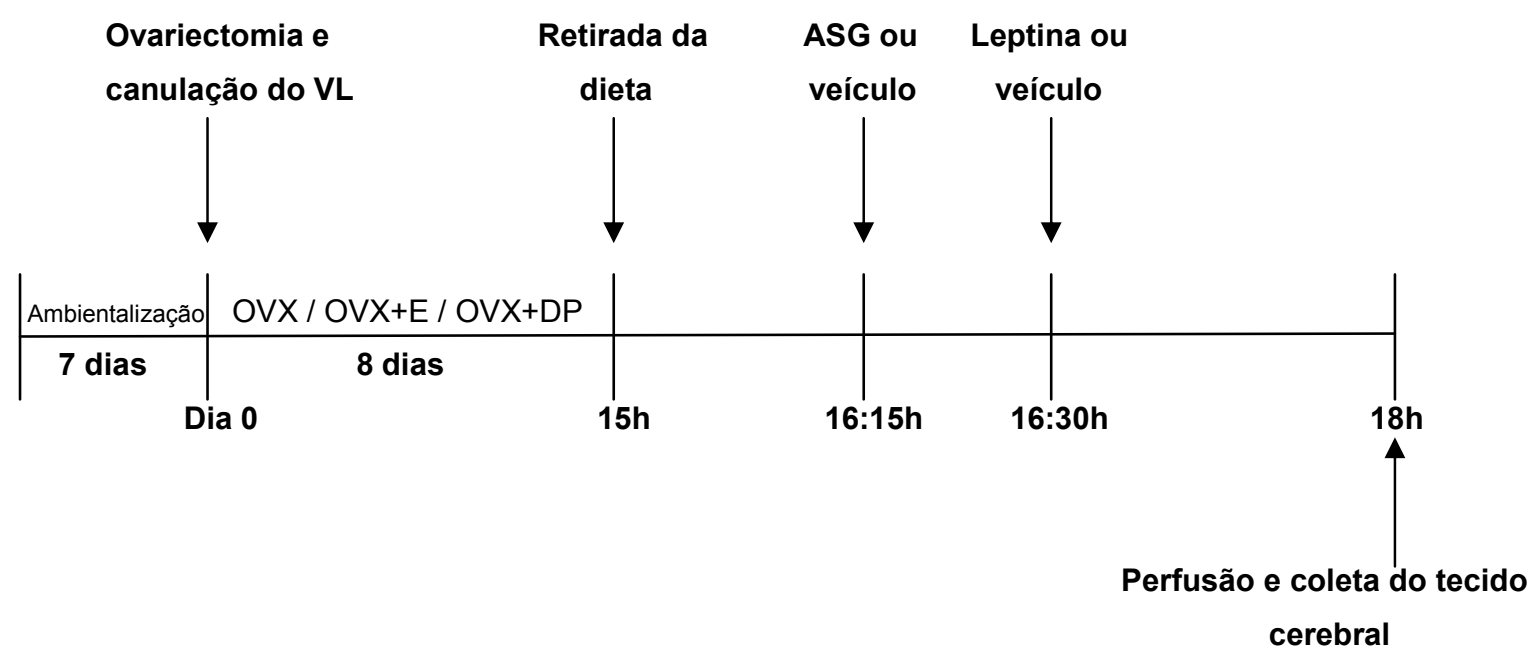

\subsection{Procedimentos cirúrgicos}

\subsubsection{Ovariectomia bilateral}

Neste estudo foram incluídas apenas ratas que apresentaram três ciclos estrais regulares e consecutivos de quatro dias. A verificação do ciclo estral foi 
realizada, coletando-se o esfregaço vaginal diariamente com um conta-gotas contendo previamente solução de $\mathrm{NaCl} 0,9 \%$. O fluido vaginal coletado foi analisado a fresco no microscópio óptico.

Após três ciclos estrais regulares, as ratas foram ovariectomizadas, sob anestesia com 2,2,2-tribromoetanol (TBE 2,5\%, 1mL/100g peso corporal, via intraperitoneal). Estes animais foram submetidos à incisão bilateral longitudinal (1,5 cm de comprimento) da pele e tecido subcutâneo entre a última costela e a coxa. Com o auxílio de uma pinça, o tecido muscular foi divulsionado para visualização dos ovários, os quais foram retirados. Após a retirada, foi realizada sutura com fio de algodão.

\subsubsection{Canulação do ventrículo lateral}

Logo após a ovariectomia, as ratas foram submetidas à implantação de uma cânula intracerebroventricular (icv) por meio de cirurgia estereotáxica. Durante esta cirurgia, os animais receberam um implante no ventrículo lateral direito de uma cânula guia de aço inoxidável de 0,6 mm de diâmetro externo, 0,4 mm de diâmetro interno e $10 \mathrm{~mm}$ de comprimento. O animal teve sua cabeça fixada num aparelho estereotáxico e uma incisão na parte superior da mesma foi realizada, expondo-se o bregma e o lâmbda. Um ajuste foi realizado para que estes pontos ficassem no mesmo plano horizontal. Após o implante, a cânula foi fixada por uma resina de acrílico autopolimerizável $\left(\right.$ Simplex ${ }^{\circledR}$ ) sobre a calota craniana, com auxílio de parafusos de aço inoxidável fixados no crânio para assegurar uma maior adesão do polímero ao osso. 
A cânula no ventrículo lateral direito foi posicionada utilizando-se as seguintes coordenadas do atlas de Paxinos e Watson (1997): ântero-posterior: -0,6 $\mathrm{mm}$ (posterior ao bregma); látero-lateral: $-1,5 \mathrm{~mm}$ (direita ao bregma); vertical: $-3,6$ $\mathrm{mm}$ (a partir da superfície da calota craniana). Dentro de cada cânula foi inserido um mandril de aço para evitar a obstrução.

Ao final da cirurgia, os animais receberam uma injeção de antibiótico (Pentabiótico) na dose de: $0,1 \mathrm{~mL} / 100 \mathrm{~g}$ peso corporal, por via intramuscular.

A posição da cânula foi verificada por meio da injeção central de corante (azul de Evans) após o término do experimento e realização de tratamento histológico.

\subsection{Coleta de sangue}

O sangue do tronco foi coletado por decapitação em tubos contendo heparina, sob gelo. O plasma foi obtido após centrifugação por 20 minutos, 3.000 rotações/min, a $4^{\circ} \mathrm{C}$ e posteriormente estocado a $-20^{\circ} \mathrm{C}$, até o momento das dosagens.

\subsection{Perfusão cerebral}

Os animais foram anestesiados com tribromoetanol 2,5\% (1mL/100g) e, após o desaparecimento dos reflexos raqui-medulares, foram submetidos à perfusão do SNC. No momento da perfusão foi palpada a região terminal do esterno onde então foi realizado um corte na pele e na musculatura subjacente do abdome. 
As regiões laterais das costelas foram seccionadas, visualizando-se o coração, que foi isolado das estruturas adjacentes, rebatendo-se o timo a fim de visualizar o ápice cardíaco e a saída do arco aórtico. A aorta torácica descendente foi visualizada e ocluída antes de sua passagem pelo hiato da aorta no diafragma. Levantando-se o coração, foi realizado um corte no ápice do ventrículo esquerdo, sendo, a seguir, introduzida uma agulha romba até a saída da aorta. Um corte foi realizado no átrio direito para permitir a saída do sangue e do líquido após a perfusão cerebral. A perfusão foi iniciada com a infusão de $200 \mathrm{~mL}$ de solução salina isotônica estéril ( $\mathrm{NaCl}$ 0,9\%) com heparina (diluição 1:80) seguida pela infusão de $400 \mathrm{~mL}$ de paraformaldeído $4 \%$. Neste procedimento foi utilizada uma bomba peristáltica com velocidade de infusão de $15 \mathrm{~mL} /$ minuto. O tecido cerebral foi pós-fixado em paraformaldeído $4 \%$ por $1 \mathrm{~h}$, e após este período foi estocado em uma solução de sacarose $30 \%$ a $4^{\circ} \mathrm{C}$ por quatro dias, quando realizou-se os cortes histológicos em criostato.

\subsection{Métodos laboratoriais}

\subsubsection{Radioimunoensaio da corticosterona}

A corticosterona plasmática foi determinada pelo método de Vecsei e colaboradores (1979), que utiliza a extração do esteróide com etanol. Foi utilizado um anticorpo anti-corticosterona (Sigma, AB-cort-17984) preparado em coelhos, com

o hormônio conjugado com albumina bovina. A corticosterona [1,2-3(H)] (New England Nuclear) foi utilizada como hormônio marcado. Na separação da fração livre 
da ligada foi utilizada uma solução de carvão-dextran $0,5 / 0,05 \%$. A dose mínima detectável e o coeficientes de variação intra foram $0,4 \underline{ \pm} \mu \mathrm{g} / \mathrm{dL}$ e $5,1 \%$, respectivamente.

\subsubsection{Dosagem de leptina plasmática}

A dosagem de leptina plasmática foi realizada por radioimunoensaio com duplo anticorpo, utilizando-se kit comercial (Linco). A dose mínima detectável e o coeficiente de variação intra-ensaio foram $0,1 \mathrm{ng} / \mathrm{mL}, 1,5 \%$, respectivamente.

\subsubsection{Imunoistoquímica}

Os tecidos cerebrais foram seccionados em cortes de $30 \mu \mathrm{m}$ de espessura utilizando-se um criostato. Realizou-se o bloqueio da peroxidase endógena com solução $\mathrm{H}_{2} \mathrm{O}_{2}(0,3 \%)$ e também o bloqueio das ligações inespecíficas utilizando-se soro normal da espécie apropriada. Posteriormente, para visualização da expressão da proteína Fos, os cortes foram incubados em temperatura ambiente por 12-14 horas com o anticorpo primário anti-Fos (Ab-5, Oncogene 1:10.000) e a seguir, incubados com o segundo anticorpo biotinilado (Vector Laboratories, Califórnia, USA, 1:200) por um período de 1 hora. Para a coloração, foi utilizado o complexo avidina-biotina-peroxidase (Vectastain, Vector Laboratories, Califórnia, USA, 1:200), empregando diaminobenzidina (DAB) e cloreto de níquel como cromógenos, cuja reação confere ao núcleo das células neuronais uma coloração de violeta escuro a preto. 
No protocolo de co-localização, o protocolo básico de imunoistoquímica foi seguido. No segundo dia, após o término do protocolo descrito acima, foi utilizado anticorpo anti-CART (Rabbit monoclonal Phoenix Pharmaceuticais, Califórnia, USA, 1:10000). A revelação foi realizada com DAB não intensificada com níquel, da mesma maneira como descrito anteriormente.

\subsubsection{Western blotting para determinação da expressão de UCP-1}

O tecido adiposo marrom foi homogenizado em tampão de sacarose (sacarose 300 mM e Triton X-100 1\%) na seguinte proporção: $5 g$ de tecido para cada $100 \mathrm{~mL}$ de tampão. Após a homogenização, as amostras foram centrifugadas a 2500 rpm por 10 minutos, a $4^{\circ} \mathrm{C}$. Posteriormente, foi retirada a camada de lipídio e o sobrenadante foi transferido para outro microtubo.

A partir do sobrenadante, foi realizada a dosagem de proteína das amostras em duplicata, pelo método de Bradford (Protein Assay, Bio-Rad), em espectrofotômetro com comprimento de onda de 562 nm. As amostras contendo 10 $\mu \mathrm{g}$ de proteínas foram solubilizadas em tampão da amostra pH 6,8 (20\% de glicerol, Tris $1 \mathrm{M} \mathrm{pH} 6,8$, SDS $4 \%$, DTT $0,1 \mathrm{M}$, azul de bromofenol $0,02 \%$ ) a $100^{\circ} \mathrm{C}$ por 3 minutos e aplicadas em gel de eletroforese SDS-PAGE $10 \%$, com 0,75 mm de espessura. A eletroforese foi realizada a $90 \mathrm{~V}$ por 90 minutos. As proteínas do gel foram transferidas para a membrana de nitrocelulose $0,45 \mathrm{~mm}$ Trans Blot por meio do sistema de tanque ligado a $100 \mathrm{~V}$ por 90 minutos. Em seguida, a membrana foi incubada em solução de bloqueio (TBS-T e 10\% de leite em pó desnatado) por 90 minutos. Após 5 lavagens de 5 minutos com solução TBS-T, a membrana foi incubada com anticorpo primário anti- $\beta$-actina (Cell Signaling Technology) na 
diluição de 1:750 em solução contendo TBS-T e albumina de soro bovino. A incubação ocorreu sob agitação, a $4^{\circ} \mathrm{C}$, overnight. Posteriormente, a membrana foi submetida a 5 lavagens de 5 minutos com solução TBS-T e incubada com anticorpo secundário anti-lgG de coelho conjugado à peroxidase (Cell Signaling Technology), na diluição de 1:3000 em solução contendo TBS-T e albumina de soro bovino. A incubação ocorreu sob agitação, em temperatura ambiente por 1 hora. Em seguida, a membrana foi lavada em solução TBS-T e incubada por 6 minutos com a mistura de reagentes do kit de quimiluminescência amplificada (ECL Plus, Amersham Biosciences). A detecção por quimioluminescência foi realizada em sistema de detecção Chemidoc XRS + Imaging System (Bio-Rad), com exposição de 60 segundos.

Posteriormente, a membrana foi lavada 5 vezes de 5 minutos em solução TBS e realizou-se o procedimento de recuperação da membrana com solução Restore Western Blot Stripping Buffer (Thermo Scientific), sob agitação por 15 minutos em temperatura ambiente. A membrana foi lavada com TBS-T e realizouse novamente o bloqueio (TBS-T e 10\% de leite em pó desnatado) por 90 minutos. Após 5 lavagens de 5 minutos com solução TBS-T, a membrana foi incubada com anticorpo primário anti-UCP-1 (Santa Cruz Biotechnology, Califórnia, USA) na diluição de 1:1750 em solução contendo TBS-T e albumina de soro bovino. A incubação ocorreu sob agitação, a $4^{\circ} \mathrm{C}$, overnight. Posteriormente, a membrana foi submetida a 5 lavagens de 5 minutos com solução TBS-T e incubada com anticorpo secundário anti-lgG de cabra produzido em coelho conjugado com peroxidase (Santa Cruz Biotechnology, Califórnia, USA), na diluição de 1:5000 em solução contendo TBS-T e leite desnatado. A incubação ocorreu sob agitação, em temperatura ambiente por 1 hora. A membrana foi lavada novamente em solução 
TBS-T e incubada por 6 minutos com a mistura de reagentes do kit de quimiluminescência amplificada (ECL Plus, Amersham Biosciences). A detecção por quimioluminescência foi realizada em sistema de detecção Chemidoc XRS + Imaging System (Bio-Rad), com exposição de 60 segundos.

\subsection{Análise estatística}

Os resultados foram apresentados como média \pm erro padrão da média (EPM). A significância estatística da diferença entre as médias dos grupos estudados foi avaliada pela análise de variância (ANOVA): one-way ANOVA, seguido do pós-teste Student-Newman-Keuls, para análise dos experimentos com uma variável (Protocolo Experimental 1); three-way ANOVA, seguido do pós-teste Student-Newman-Keuls, para análise dos experimentos com três variáveis (Protocolos Experimentais 2 e 3). O nível de significância adotado foi de 5\%. 
4. RESULTADOS 
4.1. Avaliação da ingestão alimentar e do peso corporal em ratas

\section{ovariectomizadas com e sem reposição de estradiol}

A figura 1 apresenta o resultado de ingestão alimentar diária (g/100g peso corporal) durante os sete dias seguintes à cirurgia de ovariectomia bilateral com reposição de cipionato de estradiol na dose de $10 \mu \mathrm{g} / \mathrm{Kg}$ peso corporal $(\mathrm{OVX}+\mathrm{E})$ ou óleo de milho $(\mathrm{OVX}$ e OVX+DP). Observa-se que o tratamento diário com cipionato de estradiol levou a uma menor ingestão alimentar a partir do $3^{\circ}$ dia de tratamento (Figura $1 \mathrm{~A} ; \mathrm{p}<0,05)$ e menor ingestão alimentar acumulada durante todo o período de tratamento (Figura 1B; $75,6 \pm 5,4 \mathrm{~g} / 100 \mathrm{~g}$ peso corporal; $\mathrm{n}=7-13$; $p<0,05)$, quando comparado aos animais ovariectomizados tratados com veículo $(89,4 \pm 15,5 \mathrm{~g} / 100 \mathrm{~g}$ peso corporal $)$.

A

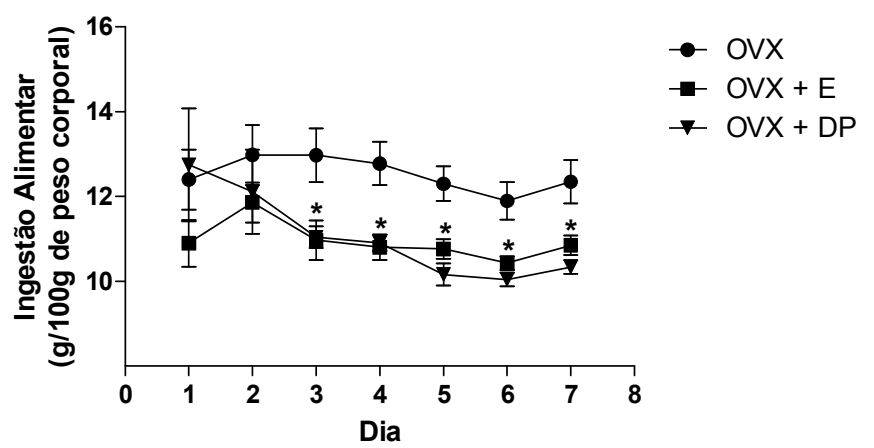

B

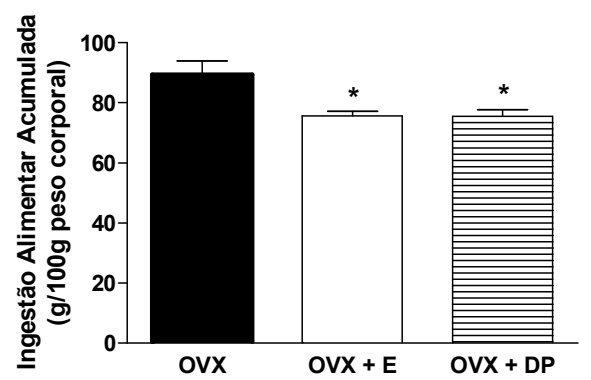

Figura 1: Efeito do tratamento com cipionato de estradiol sobre a ingestão alimentar diária $(A)$ e acumulada (B). $\quad N=15-20$. Valores expressos como média \pm EPM. ${ }^{*} p<0,05$ comparado ao grupo OVX. 
Na Figura 2A observamos que a injeção subcutânea de cipionato de estradiol induziu menor ganho de peso diário em ratas ovariectomizadas, a partir do $5^{\circ}$ dia de tratamento, quando comparado aos animais que receberam veículo. Além disso, o ganho total de peso corporal também foi menor nos animais que receberam o tratamento com cipionato de estradiol (Figura 2B; OVX: 47,9 $\pm 1,9 \mathrm{~g}$; OVX+E: 31,9 $\pm 1,90 \mathrm{~g} ; \mathrm{p}<0,001, \mathrm{n}=20)$. Entretanto, o pareamento da dieta não foi capaz de induzir a mesma redução no ganho de peso, uma vez que os animais ovariectomizados que receberam dieta pareada ao grupo tratado com estradiol apresentaram a mesma variação no peso corporal observada no grupo tratado com veículo e ração ad libitum (OVX+DP: 47,6 + 1,6g).

A

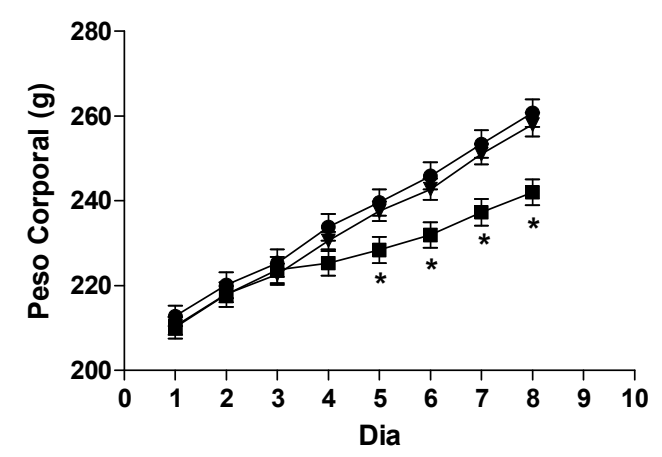

B

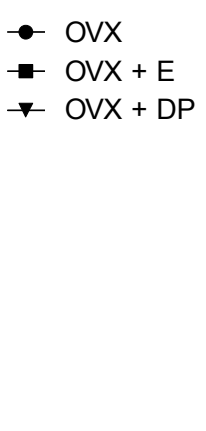

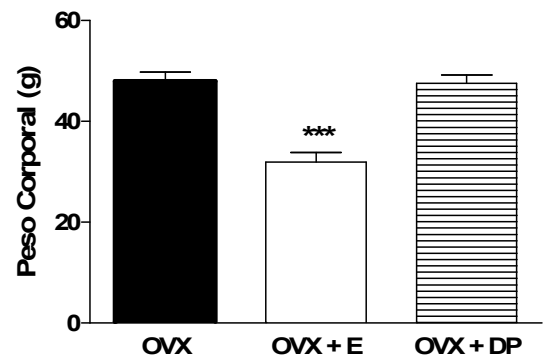

Figura 2: Efeito do tratamento com cipionato de estradiol sobre o ganho de peso corporal diário $(A)$ e total (B). $\quad N=20$. Valores expressos como média \pm EPM. ${ }^{*} p<0,05$ e ${ }^{* \star *} p<0,001$ comparado ao grupo OVX. 

todos os grupos (Figura 3).

A

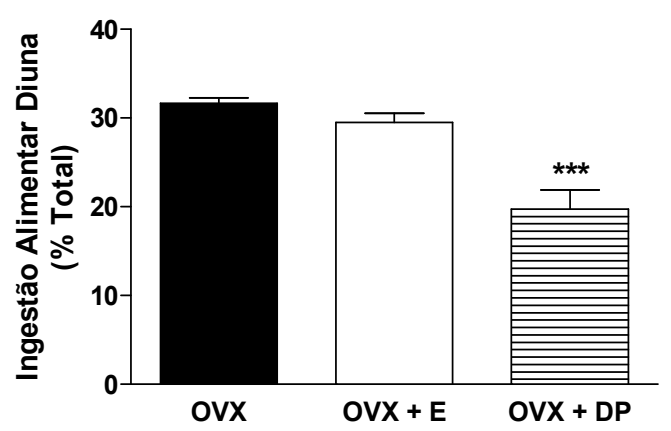

B

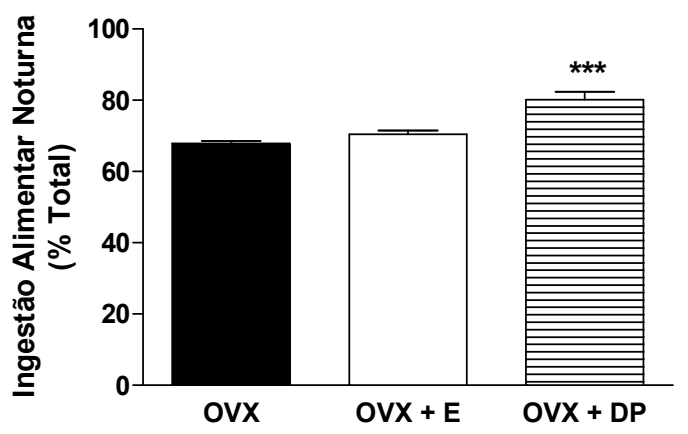

Figura 3: Efeito do tratamento com cipionato de estradiol sobre a ingestão alimentar diurna (A) e noturna (B). $\quad \mathrm{N}=6-7$. Valores expressos como média \pm EPM. ${ }^{* * *} p<0,001$ comparado ao grupo OVX.

Além disso, não foi observada alteração na ingestão de água pelos animais entre os grupos (Figura 4, OVX: 98,8 \pm 2,3 mL/100g peso corporal; OVX+E: 95,4 \pm 6,9 mL/100g peso corporal; OVX+DP: 101,1 \pm 1,3 mL/100g peso corporal; $n=6-7)$.

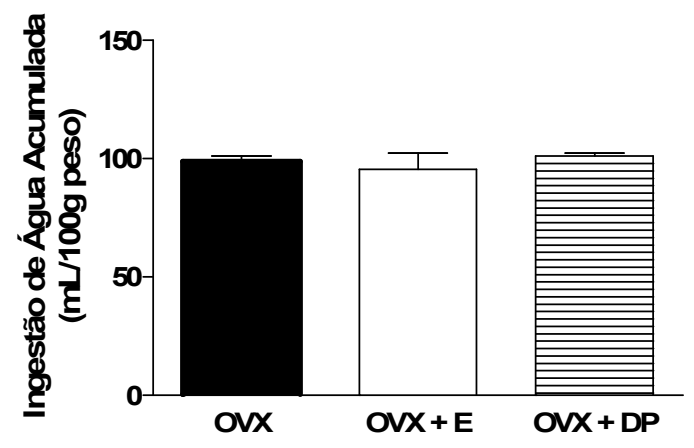

Figura 4: Efeito do tratamento com cipionato de estradiol sobre a ingestão de água acumulada. $\mathrm{N}=6-7$. Valores expressos como média \pm EPM. Não foi observada diferença estatística significativa entre os grupos. 
Como se observa na figura 5, não houve diferença significativa no peso relativo do BAT ao final do experimento (OVX: 0,12 $\pm 0,01 \mathrm{~g} / 100 \mathrm{~g}$ peso corporal; OVX+E: $0,15 \pm 0,01 \mathrm{~g} / 100 \mathrm{~g}$ peso corporal; OVX+DP: $0,14 \pm 0,02 \mathrm{~g} / 100 \mathrm{~g}$ peso corporal; $n=20)$.

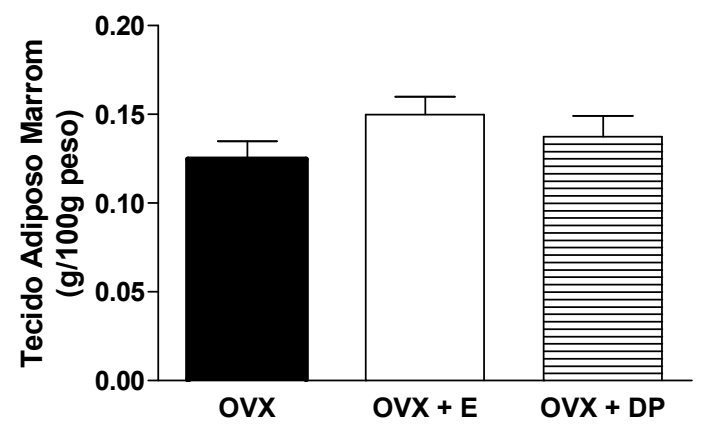

Figura 5: Efeito do tratamento com cipionato de estradiol sobre o peso relativo do tecido adiposo marrom $(n=20)$. Valores expressos como média \pm EPM. Não foi observada diferença estatística significativa entre os grupos. 


\subsection{Avaliação das concentrações plasmáticas de corticosterona e} leptina em ratas ovariectomizadas com e sem reposição de estradiol

Na figura 6 estão apresentadas as concentrações plasmáticas de corticosterona e leptina em animais OVX, OVX+E e OVX+DP decapitados às $17 \mathrm{~h}$ e 22h. Os animais que receberam a reposição com cipionato de estradiol apresentaram aumento nas concentrações plasmáticas de corticosterona tanto às 17 (OVX: 9,9 \pm 0,6 $\mu \mathrm{g} / \mathrm{dL} ;$ OVX+E: $15,8 \pm 0,8 \mu \mathrm{g} / \mathrm{dL} ;$ OVX+DP: 10,8 \pm 1,5 $\mu \mathrm{g} / \mathrm{dL}$ $p<0,001$ ) como às 22 horas (OVX: 7,1 \pm 1,3 $\mu \mathrm{g} / \mathrm{dL} ;$ OVX+E: 14,2 \pm 1,8 $\mu \mathrm{g} / \mathrm{dL}$; OVX+DP: $6,5 \pm 1,2 \mu \mathrm{g} / \mathrm{dL} ; \mathrm{p}<0,05 ; \mathrm{n}=10-11)$, quando comparado aos grupos OVX ou OVX+DP. A concentração plasmática de leptina às 17 horas do grupo OVX+E foi significativamente maior, quando comparada aos grupos OVX e OVX+DP. No entanto, às 22 horas a concentração plasmática de leptina do grupo OVX+E foi maior apenas quando comparada ao grupo OVX+DP. (OVX: 4,2 + 0,5 ng/mL; OVX+E: 5,9 + 0,7 ng/mL; OVX+DP: 3,8 + 0,5 ng/mL; $p<0,05 ; n=6)$.
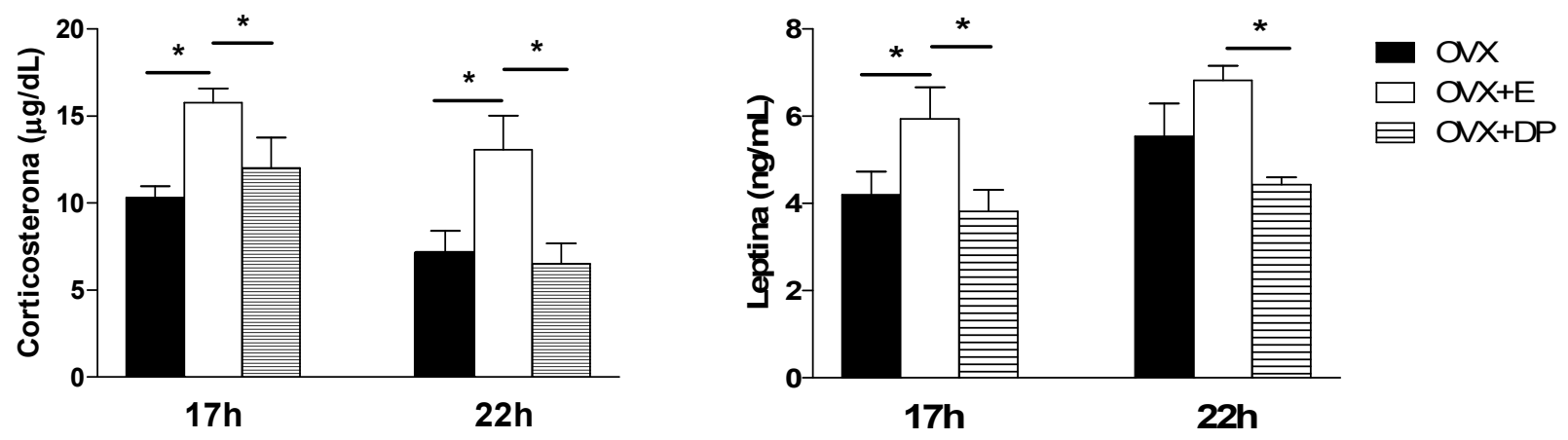

Figura 6: Efeito do tratamento com cipionato de estradiol sobre as concentrações plasmáticas de corticosterona e leptina $(n=6-11)$. Valores expressos como média \pm EPM. * $p<0,05$ 
4.3. Avaliação dos efeitos do antagonista de CRF sobre a ingestão alimentar e o peso corporal após administração central de leptina em ratas ovariectomizadas com e sem reposição de estradiol

A figura 7 representa a variação no peso corporal (g) e na ingestão alimentar (g/100g peso corporal) 14h após a realização do tratamento central com leptina. Observa-se que a leptina causou redução no ganho de peso nos animais OVX com e sem reposição com cipionato de estradiol, comparado ao respectivo grupo tratado com veículo (Figura 7A; OVX: $-2,6 \pm 0,8$ vs $5,7 \pm 0,9 \mathrm{~g}$; OVX+E: $-4,7 \pm$ $1,5 \mathrm{~g}$ vs $2,8 \pm 1,4 \mathrm{~g} ; \mathrm{p}<0,05 ; \mathrm{n}=6-7)$. O pré-tratamento com o antagonista de CRF-R2 reverteu a perda de peso induzida pela leptina apenas no grupo OVX+E (OVX+E: $3,1 \pm 1,6 \mathrm{~g}$ ). $\mathrm{O}$ mesmo resultado foi observado na ingestão alimentar (Figura 7B), ou seja, a leptina foi capaz de reduzir a ingestão de alimento nos animais OVX e OVX+E (OVX: $5,3 \pm 0,4 \mathrm{~g} / 100 \mathrm{~g}$ peso corporal vs 10,3 \pm 1,5 g/100g peso corporal; OVX+E: $5,2 \pm 0,3 \mathrm{~g} / 100 \mathrm{~g}$ peso corporal vs $8,9 \pm 0,5 \mathrm{~g} / 100 \mathrm{~g}$ peso corporal; $\mathrm{p}<0,05$ n=6-7). Contudo, somente no grupo que recebeu a reposição hormonal foi observada uma reversão na hipofagia induzida pela leptina ao receber tratamento prévio com antagonista de CRF-R2 (OVX+E: 8,5 $\pm 1,4 \mathrm{~g} / 100 \mathrm{~g}$ peso corporal). 
A

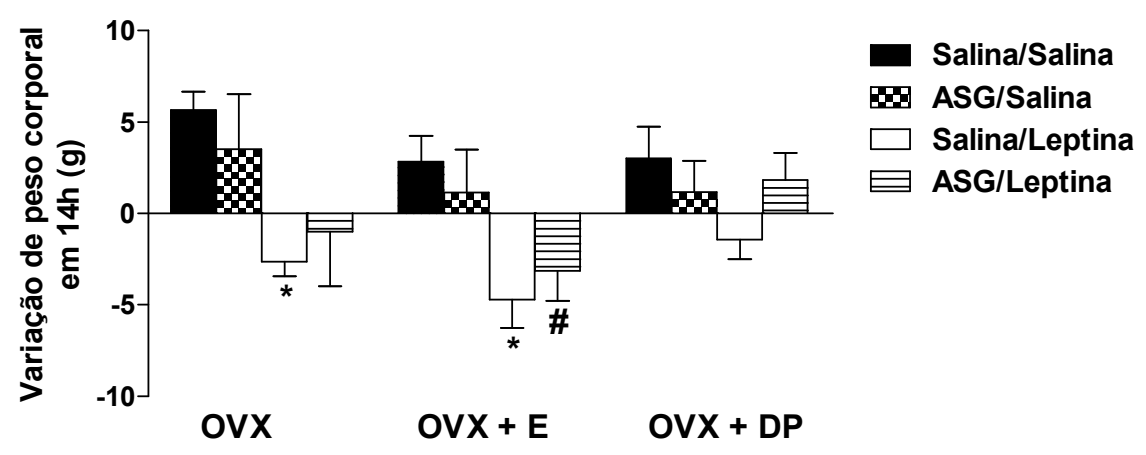

B

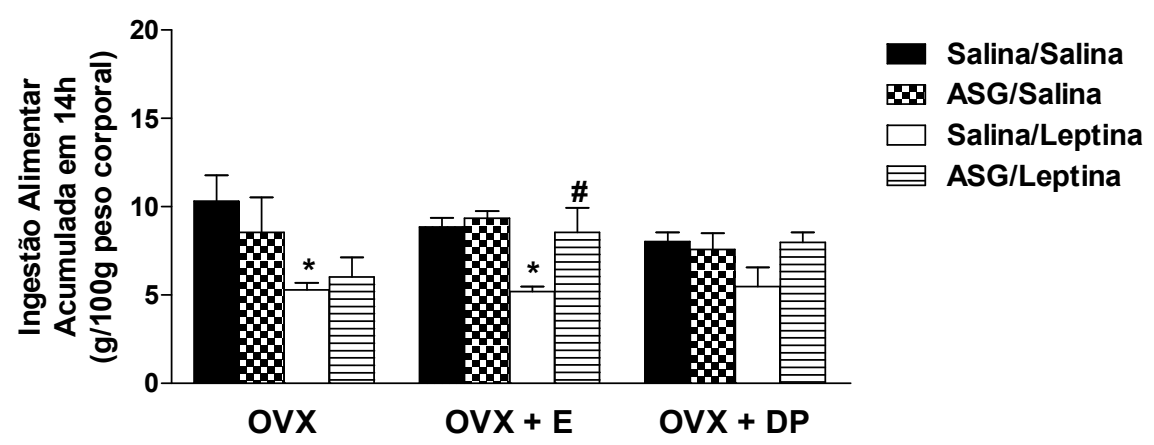

Figura 7: Efeito do pré-tratamento com antagonista de CRF-R2 (ASG) no ganho de peso corporal (A) e na ingestão alimentar $(B)$ após estímulo com leptina em ratas tratadas com estradiol $(n=6-7)$. Valores expressos como média \pm EPM. *: $p<0,001$ vs respectivo controle, $\#$ : $p<0,05$ vs salina/leptina. 
4.4. Avaliação dos efeitos do antagonista de CRF sobre a expressão protéica de UCP1 no tecido adiposo marrom após administração central de leptina em ratas ovariectomizadas com e sem reposição de estradiol

Podemos verificar na figura 8 que o tratamento com cipionato de estradiol por si só foi capaz de aumentar em $100 \%$ a expressão protéica de UCP-1 no BAT ( $n=5 ; P<0,05)$, quando comparada aos grupos OVX e OVX+DP. Alem disso, o tratamento com leptina aumentou a expressão protéica de UCP-1 em ratas castradas com e sem reposição com estradiol (OVX: 50\%; OVX+E: 70\%; P<0,05; $n=5)$. O pré-tratamento com o antagonista do CRF-R2 bloqueou $(p<0,05)$ a resposta da expressão de UCP-1 induzida pela leptina apenas no grupo OVX+E (Figura 9).

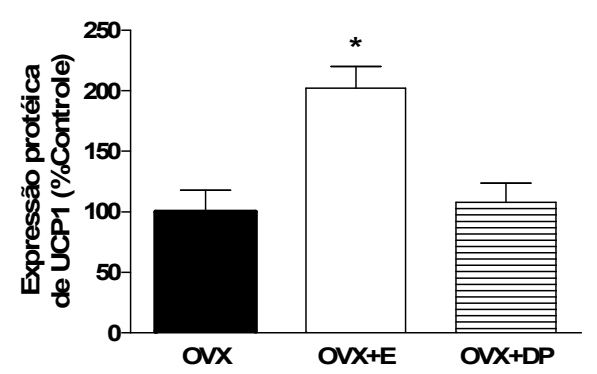

Figura 8: Efeito do tratamento com cipionato de estradiol sobre a expressão protéica de UCP-1 ( $n=$ 5). Valores expressos como média \pm EPM. ${ }^{*} p<0,05$ comparado ao grupo OVX. 


\section{UCP-1}

\section{$\beta$-actina}

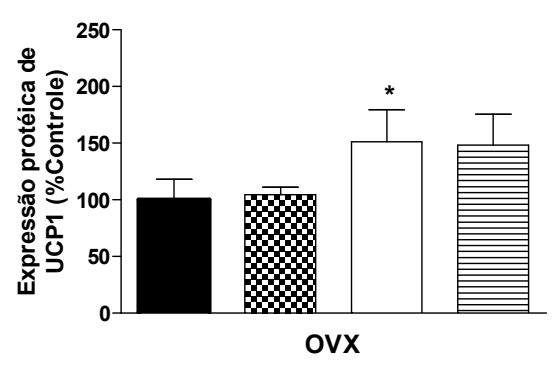

UCP-1

\section{$\beta$-actina}

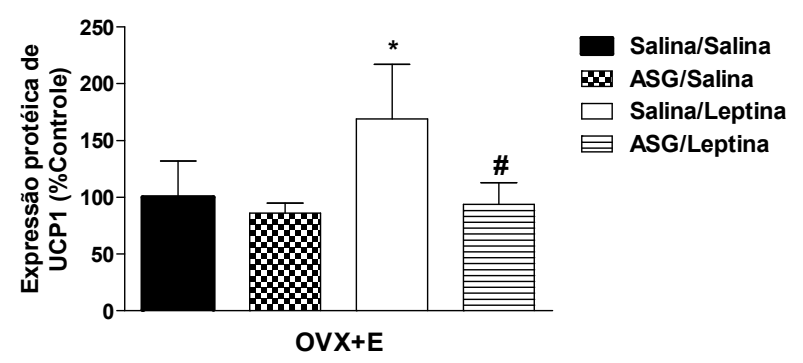

\section{UCP-1}

\section{$\beta$-actina}

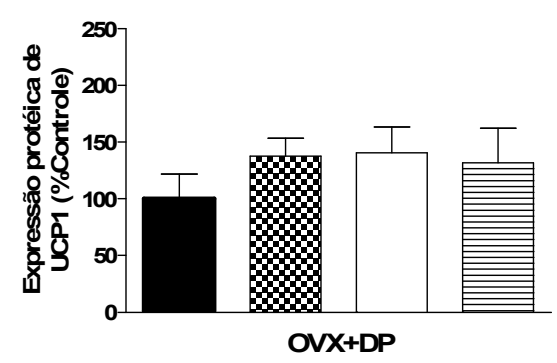

Figura 9: Efeito do pré-tratamento com antagonista de CRF-R2 (ASG) no ganho de peso corporal e na ingestão alimentar após estímulo com leptina em ratas castradas com (OVX+E) e sem reposição com cipionato de estradiol $(O V X ; O V X+D P)(n=5)$. Valores expressos como média \pm EPM. * $: p<0,05$ vs salina/salina, $\#$ : $p<0,05$ vs salina/Leptina. 
4.5. Avaliação dos efeitos do antagonista de CRF sobre a expressão de proteína Fos e CART no núcleo arqueado após administração central de leptina em ratas ovariectomizadas com e sem reposição de estradiol

A figura $10 \mathrm{~A}$ apresenta o número de neurônios imunorreativos para a proteína Fos no núcleo arqueado de ratas OVX, OVX+E e OVX+DP. Podemos observar que o tratamento central com leptina causou um aumento no número de neurônios que expressam Fos no $A R Q$ de ratas OVX, o qual foi exacerbado nas ratas que receberam tratamento com cipionato de estradiol (OVX: 5,0 \pm 0,6 vs 17,8 \pm 2,$7 ;$ OVX+E: $3,3 \pm 1,3$ vs $28,3 \pm 6,1 ; n=3-5 ; p<0,05 ;$ salina vs leptina respectivamente). O pré-tratamento com o antagonista do CRF-R2 bloqueou $(p<0,001)$ a ativação neuronal no $A R Q$ induzida pela leptina apenas no grupo OVX+E $(5,2 \pm 1,9)$

$\mathrm{Na}$ figura 10B podemos observar o número de neurônios imunorreativos para a proteína Fos e o peptídeo CART no ARQ. Houve um aumento na dupla marcação Fos/CART nos animais OVX e OVX+E após a infusão central de leptina, contudo o tratamento com cipionato de estradiol não levou à exacerbação dessa resposta (OVX: 1,7 $\pm 0,9$ vs 9,5 $\pm 1,6 ;$ OVX+E: $0,3 \pm 0,3$ vs 9,5 $\pm 2,2 ; n=3-5$ $p<0,001)$. O pré-tratamento com o antagonista do CRF-R2 bloqueou $(p<0,001)$ a ativação de neurônios CART no $A R Q$ induzida pela leptina apenas no grupo OVX+E $(1,5 \pm 0,3)$

A figura 11 apresenta fotomicrografias representativas (aumento de 40X) de secções coronais de imunoistoquímica para Fos/CART no ARQ. 
A

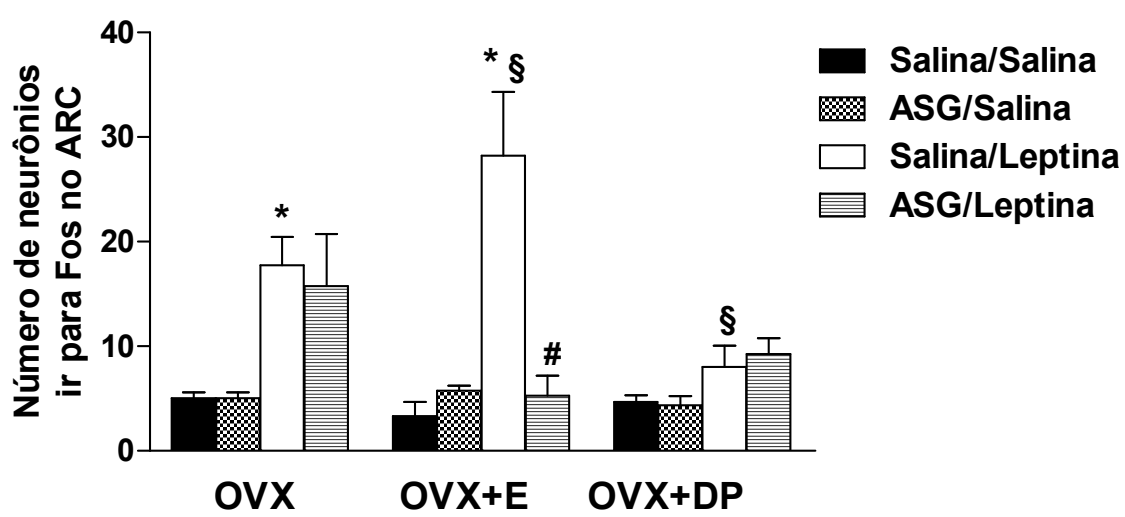

B

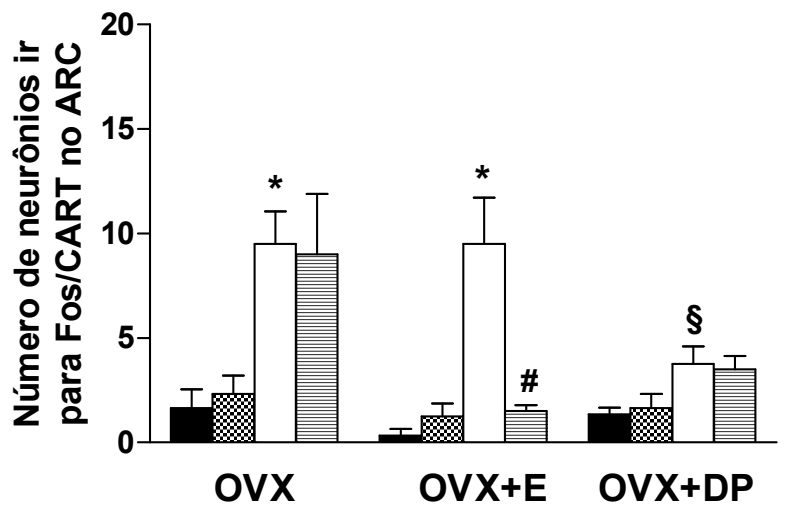

Salina/Salina
\%SG/Salina
$\square$ Salina/Leptina
$\square$ ASG/Leptina

Figura 10: Efeito do pré-tratamento com antagonista de CRF-R2 (ASG) na imunorreatividade para Fos (A) e na imunolocalização de Fos e CART (B) após estímulo com leptina em neurônios do núcleo arqueado de ratas castradas com $(\mathrm{OVX}+\mathrm{E})$ e sem reposição com cipionato de estradiol (OVX; OVX+DP) (n=3-5). Valores expressos como média \pm EPM. ${ }^{*}: p<0,05$ vs salina/salina, \# : $p<0,05$ vs salina/Leptina; $\S$ : $p<0,05$ vs OVX salina/Leptina. 
OVX

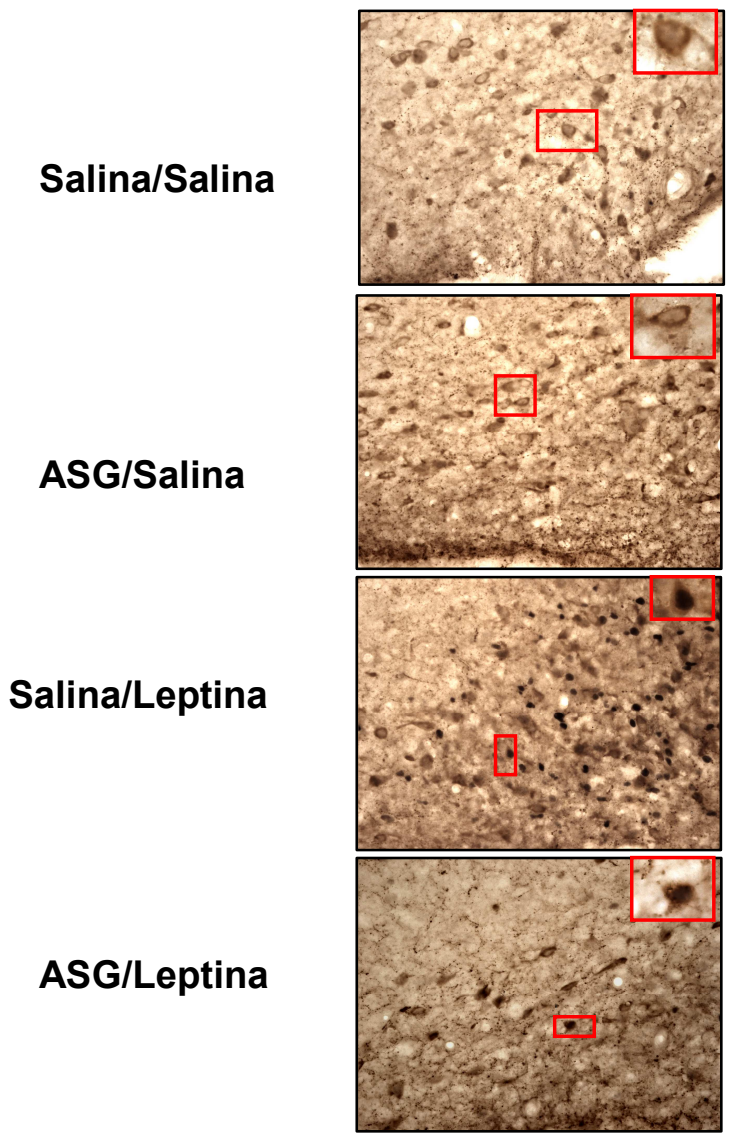

OVX+E
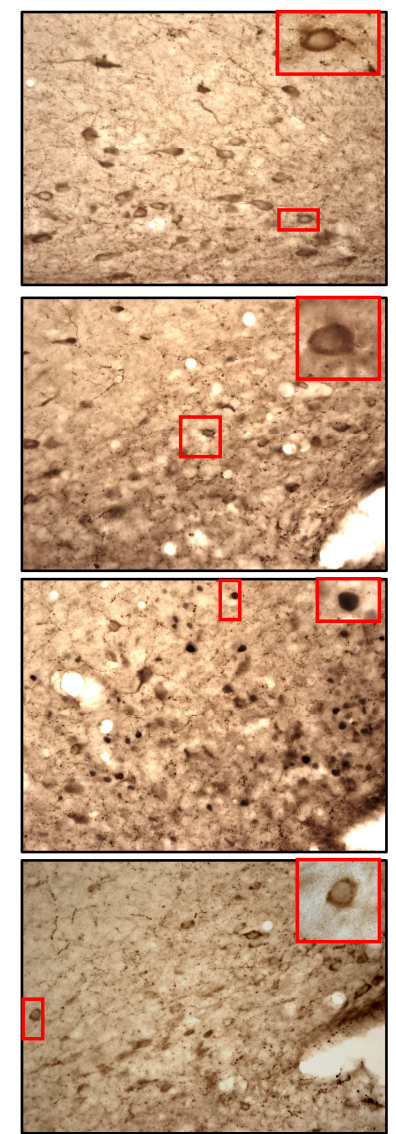

OVX+DP
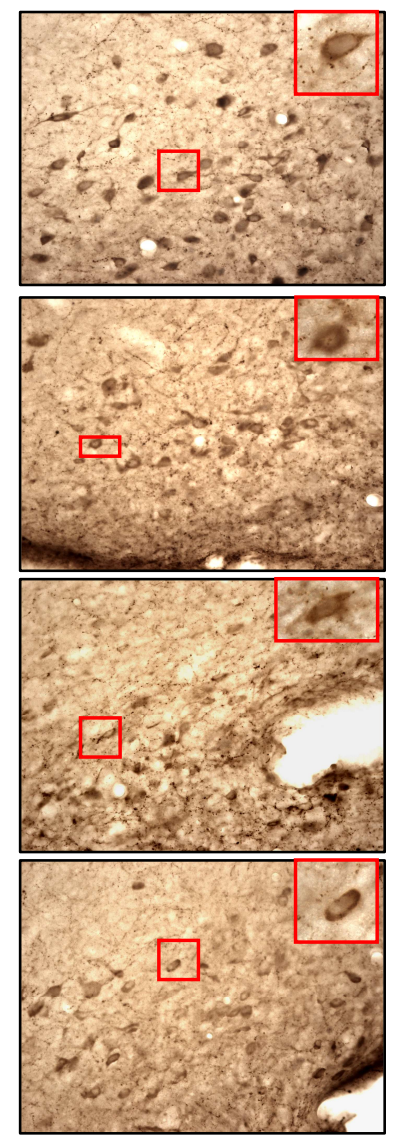

Figura 11: Fotomicrografias representativas do efeito do pré-tratamento com antagonista de CRF-R2 na imunolocalização de Fos e CART no ARQ após estímulo com leptina em ratas castradas com e sem reposição hormonal. Aumento de 40X e 100X. 
5. DISCUSSÃO 
Em nosso trabalho demonstramos que o tratamento de ratas castradas com cipionato de estradiol $(10 \mu \mathrm{g} / \mathrm{Kg}$ peso corporal, sc) reduz tanto a ingestão alimentar como o ganho de peso corporal induzido pela castração. Além disso, ocorre um aumento nas concentrações plasmáticas de corticosterona e leptina. Ainda, quando realizamos a administração de leptina no ventrículo lateral dessas fêmeas com reposição estrogênica observamos hipofagia, perda de peso corporal, aumento na expressão da proteína UCP-1 no tecido adiposo marrom e aumento na ativação neuronal no núcleo arqueado. Esses efeitos são revertidos quando realizamos administração central prévia de antisauvagina, antagonista dos receptores tipo 2 do CRF.

Nossos resultados estão de acordo com dados da literatura que demonstraram que a ovariectomia em ratas e camundongas leva a um aumento de 10 a $25 \%$ no peso corporal, sendo a maior parte devida a um aumento no tecido adiposo (Geary et al., 2001). Esse aumento no peso é atribuído a um aumento na ingestão de alimentos associado à redução na atividade física e alterações no metabolismo (Geary et al., 2001). Toth e colaboradores, 2001, utilizando ratas Sprague-Dawley castradas com reposição contínua de estradiol por meio de implante subcutâneo de dispositivo de liberação lenta, verificaram menor ganho de peso corporal nos animais tratados com o estrógeno. Além disso, o tratamento cíclico com estradiol é capaz de manter o ganho corporal diário semelhante ao de ratas intactas (Asarian \& Geary, 2002). O estradiol reduz a massa de tecido adiposo, sendo essa uma das causas da redução de peso nas ratas tratadas (Salas et al., 2005).

A ingestão alimentar varia durante o ciclo menstrual em mulheres e durante o ciclo estral em roedores. No período periovulatório a ingestão alimentar 
pode ser até $25 \%$ menor que nas outras fases do ciclo, isso tem sido atribuído ao pico estrogênico característico dessa fase (Asarian \& Geary, 2006). Além disso, a gonadectomia em fêmeas leva a um aumento da ingestão alimentar, o que revela a importância do funcionamento correto do eixo hipotálamo-hipófise-gônadas no comportamento alimentar (Asarian \& Geary, 2006). Assim, nossos dados de menor ingestão alimentar no grupo OVX+E são consistentes com os dados da literatura.

O efeito hipofágico do estradiol em roedores já foi demonstrado em diversos trabalhos (Geary et al., 2001; Asarian \& Geary, 2002; Roesch, 2005; Santollo et al., 2007; Thammacharoen et al., 2008). Santollo e colaboradores, em 2007, observaram que a injeção subcutânea única de $4 \mu \mathrm{g}$ de estradiol por rata é capaz de reduzir a ingestão alimentar desses animais 24 horas após o tratamento. Em nosso trabalho, essa redução só foi observada a partir do quarto dia de tratamento, possivelmente devido à menor dose de tratamento.

Aparentemente, o efeito hipofágico dos estrógenos se deve à sua ligação aos receptores de estrógenos do tipo a (ERa) (Santollo et al., 2007), os quais se encontram amplamente expressos no núcleo arqueado, hipotálamo ventromedial e hipotálamo dorsomedial, importantes áreas envolvidas na homeostase energética (Shughrue et al., 1997). Na década de 90, Simerly e cols realizaram o mapeamento das áreas cerebrais de rato que expressam o RNAm para o receptor estrogênico e verificaram sua presença em diversas áreas hipotalâmicas, como a zona periventricular, as áreas mediana e anteroventral dos núcleos periventriculares da região preóptica, o $A R Q$, nas três áreas dos núcleos periventriculares, na zona dorsal da parte medial parvicelular do PVN, além da zona medial do hipotálamo. Posteriormente, Laflamme e cols, 1998, utilizando sondas específicas para as isoformas $\alpha$ e $\beta$ do receptor estrogênico, evidenciaram distribuição do RNAm da 
isoforma a semelhante àquela do trabalho anterior, indicando que a sonda utilizada por Simerly e cols era seletiva para a isoforma $\alpha$. Recentemente, estudos com camundongos knockout para ERa foram apresentados na literatura para elucidação da ações do estradiol mediadas pela isoforma a no controle da ingestão alimentar. Constatou-se que o ERa é necessário para os efeitos restritivos do estrógeno na ingestão alimentar, adiposidade e peso corporal em fêmeas, uma vez que a reposição estrogênica em fêmeas OVX knockout para ERa não é capaz de reverter os efeitos da cirurgia nesses parâmetros (Geary et al., 2001). Utilizando agonistas específicos para a isoforma a (4,4',4"'-(4-Propyl-[1H]-pyrazole-1,3,5-triyl)trisphenol ou PPT) ou para a isoforma $\beta$ (2,3-Bis(4-hydroxyphenil)-propionitrile ou DPN), Roesh, 2005, concluiu que ERa é responsável pela redução na ingestão alimentar e no ganho de peso induzido pelos estrógenos, não havendo participação de ERß nesses parâmetros, dados corroborados por Santollo e cols em 2007. Ainda, implantes estrogênicos na região do tronco encefálico, caudal à área postrema, são capazes de inibir a ingestão alimentar e ativar neurônios que expressam ERa no NTS caudal, indicando que um dos mecanismos através dos quais os estrógenos inibem a ingestão alimentar é aumentando a ativação de aferências vagais relacionadas aos sinais de saciedade, como a CCK (Tammacharoen et al., 2008).

Em nosso trabalho, verificamos que o grupo OVX com pareamento da dieta apresentou o mesmo ganho de peso, quando comparado ao grupo OVX com dieta ad libitum. Resultado semelhante foi observado por Roesch, em 2005, o qual verificou que a redução na ingestão alimentar não é suficiente para a redução de peso induzida pelos estrógenos. Foi demonstrado que o pareamento da dieta não é capaz de reduzir o ganho de peso induzido pela ovariectomia (Mueller \& Hsiao, 1980), sugerindo que os estrógenos também são capazes de reduzir o ganho de 
peso por meio de modulação na atividade locomotora e/ou na taxa metabólica de repouso (Wade, 1972). Por outro lado, o peso corporal semelhante entre o grupo OVX e OVX+DP, sugere que a dieta pareada, com restrição alimentar moderada, pode induzir respostas adaptativas que permitem a manutenção do peso corporal.

O núcleo supraquiasmático $(\mathrm{SCN})$ do hipotálamo é considerado o relógio gerador dos ritmos circadianos em mamíferos. A atividade neuronal do SCN é influenciada por diferentes fatores sincronizadores, como ciclo claro-escuro e alimentação, e auxilia no controle de uma série de comportamentos e processos fisiológicos (Herzog \& Schwartz, 2002). O SCN possui numerosas interconexões com outras regiões cerebrais, como o PVN, LH e VMH, amplamente relacionados ao controle da ingestão alimentar (Strubbe \& Woods, 2004). Os ratos são animais noturnos, ou seja, se encontram ativos principalmente durante a noite. Em condições experimentais, em que esses animais são mantidos em ciclos de 12 horas claroescuro, quando a disponibilidade de alimento é livre, a maior parte da ingestão alimentar total ocorre durante o período escuro, havendo picos no início e no final dessa fase (Strubbe \& Woods, 2004). Dessa forma, optou-se por disponibilizar alimento ao grupo com dieta pareada no período escuro, para manutenção da ingestão alimentar predominantemente no período noturno no grupo com dieta pareada.

Observamos um aumento nas concentrações plasmáticas de corticosterona no grupo tratado com estradiol. Tem sido sugerido que esse aumento da corticosterona se deva a um aumento na liberação basal estimulada pelo ACTH e PRL e por um aumento na síntese de AMPc nas células da zona fasciculata da glândula adrenal (Lo et al., 2000). 
Os níveis leptinêmicos foram maiores às 17 horas nas ratas que receberam a reposição estrogênica em nosso estudo. Sabe-se que a leptina está envolvida não apenas na regulação do peso corporal e do metabolismo, mas também na função reprodutiva. Uma vez que receptores de estrógenos se encontram expressos em adipócitos, Brann e cols, 1999, verificaram que o estradiol é capaz de regular a expressão do gene da leptina. Os autores observaram que o tratamento com 17- $\beta$-estradiol induz um aumento significativo no RNAm da leptina no tecido adiposo de ratas. Ainda, foi observado um aumento na concentração plasmática de leptina após tratamento com estradiol em dose semelhante (Silva et al., 2010) e maior (Alonso et al., 2007) à utilizada em nosso trabalho. Contudo, Rocha e cols, 2004, não verificaram alteração na leptina plasmática de ratas intactas tratadas com estradiol. Além disso, Yan $\mathrm{Ng}$ e cols, 2010, observaram, contraditoriamente, um aumento na concentração plasmática de leptina após a OVX. Essas diferenças em relação ao nosso estudo podem ser devidas aos diferentes modelos experimentais, uma vez que no primeiro trabalho foram utilizadas ratas intactas que recebiam reposição estrogênica na dose de 0,15 - 0,20 mg/dia e no segundo trabalho as fêmeas não receberam reposição hormonal após a ovariectomia.

Após a realimentação, ou seja, nas amostras coletadas às 22 horas, não foi observada diferença nas concentrações plasmáticas de leptina entre os animais $\mathrm{OVX}$ e OVX+E, as quais foram maiores que as concentrações de leptina às 18 horas. Sabe-se que as concentrações plasmáticas de leptina além de serem reguladas pela massa de tecido adiposo também sofrem influência da ingestão energética aguda. Dessa forma, em situações de jejum ou restrição energética há redução na leptina plasmática, a qual aumenta rapidamente após a realimentação 
ou superalimentação (Havel, 2000), como observado em nosso estudo. Sugere-se que a insulina seja responsável por induzir essas alterações a curto prazo na liberação de leptina, uma vez que o aumento da insulinemia precede o aumento da leptinemia (Havel, 2000; Badman \& Flier, 2007).

Nos experimentos realizados com injeção central de leptina, observamos que houve redução tanto no ganho de peso corporal, quanto na ingestão alimentar nos grupos OVX e OVX+E. A colocalização de OBRb e ERa no hipotálamo sugere uma interação na regulação de mecanismos comportamentais e neuroendócrinos (Diano et al., 1998). Clegg e cols, 2006, verificaram que a presença ou não de estrógeno altera a sensibilidade central à leptina. Dessa forma, os autores sugerem que quando os níveis estrogênicos encontram-se baixos, a sensibilidade central à leptina encontra-se reduzida.

As concentrações plasmáticas de leptina são mais elevadas em fêmeas, mesmo antes da puberdade. Após esta, o estrógeno e a testosterona modulam a síntese e secreção de leptina por meio de mecanismos transcricionais dependentes da ligação a receptores esteróides (Demerath et al., 1999; Shimizu et al., 1997; Machinal et al., 1999).

Estudo utilizando camundongas C57BL/6 castradas e com reposição estrogênica subcutânea, obteve resultado semelhante ao nosso com ratas Wistar, uma vez que os autores observaram que 12 horas após injeção central de leptina os animais tratados com estradiol apresentaram redução tanto na ingestão alimentar quanto no ganho de peso corporal, e essas alterações permaneceram até o final do experimento, 36 horas após a injeção central. Além disso, os autores verificaram que a reposição estrogênica é capaz de reverter a insensibilidade central à leptina gerada pela obesidade induzida por dieta hipercalórica (Matyskova et al., 2010). 
O CRF, além de atuar como principal secretagogo do ACTH, estando, portanto, associado ao controle da atividade do eixo hipotálamo-hipófise-adrenal, tem participação bem estabelecida no controle da homeostase energética. $\mathrm{Na}$ década de 90, Krahn e cols demonstraram que a infusão icv de CRF é capaz de reduzir a ingestão alimentar em ratos. O receptor tipo 2 do CRF tem sido apontado como principal mediador dos efeitos do CRF na supressão da ingestão alimentar (Contarino et al., 2000; Tabarin et al., 2007), e encontra-se expresso em áreas cerebrais como o septo lateral, VMH, amígdala e NTS (Hauger et al., 2003).

A redução na ingestão alimentar e no ganho de peso foi demonstrada após a infusão central de CRF em ratos machos intactos. Além disso, com a administração concomitante de ASG30 é possível reverter esses efeitos (Cullen et al., 2001). Sugere-se que o CRF induza um balanço energético negativo pela ativação do SNS e da redução na ingestão alimentar (Cullen et al., 2001). Também foi demonstrado que o CRF causa a inibição do esvaziamento gástrico (Martinez et al., 1998).

A castração causa redução na expressão de RNAm de CRF no PVN, que é revertida com a reposição estrogênica (Pelletier et al., 2007). Em nosso modelo, verificamos que a administração prévia de um antagonista seletivo dos receptores tipo 2 do CRF é capaz de reverter a hipofagia induzida pela administração central de leptina somente em ratas castradas com reposição estrogênica, indicando que o CRF é importante na modulação dessa via. Por meio da técnica de imunoistoquímica, observou-se que a leptina ativa neurônios hipotalâmicos no PVN, VMH, DMH e ARQ, e que a administração prévia de $\alpha-C R F$ (antagonista não seletivo do $\mathrm{CRF}$ ) atenua a ativação neuronal no $\mathrm{PVN}$ e $\mathrm{VMH}$. Assim, sugere-se que neurônios em ambos os núcleos recebem o estímulo da 
leptina não apenas diretamente, mas também indiretamente via neurônios CRF (Masaki et al., 2003). O ARQ recebe projeções aferentes neuronais de outras áreas periventriculares, como PVN e MPOA, e da LHA, além de áreas extrahipotalâmicas, como amígdala e NTS. Além disso, o ARQ possui projeções eferentes para a LHA, PVN, MPOA, DMH (Berthoud, 2002).

Uehara e cols, 1998, demonstraram que a administração central concomitante de a-CRH e leptina é capaz de atenuar o efeito anorexígeno da leptina. Os autores sugerem que o $\mathrm{CRH}$ seja um mediador a curto prazo dos efeitos da leptina na ingestão alimentar. Garder e cols, 1998, sugerem que o CRF atua em conjunto com outros mediadores, uma vez que os efeitos da leptina na ingestão alimentar e no peso corporal são atenuados, mas não abolidos pelo antagonista não seletivo D-Phe CRF.

Não foi observada alteração significativa no peso do BAT após tratamento com estradiol em nosso estudo, contudo, Kemnitz e colaboradores, em 1983, observaram que ratas castradas tratadas com estradiol apresentavam aumento no peso do tecido adiposo marrom, o qual foi atribuído a um aumento no conteúdo lipídico desse tecido. Ainda, Bartness \& Wade, 1984, demonstraram que o tratamento com estrógeno é capaz de aumentar a massa de tecido adiposo marrom, o qual apresenta maior conteúdo protéico, quando comparado aos animais não tratados. Além disso, esses animais apresentam aumento na termogênese, demonstrado pelo aumento no consumo de oxigênio em repouso. Entretanto, Remesar e cols, 2002, utilizando ratos Zucker tratados com solução contendo estradiol via oral durante 10 dias, não observaram alteração no peso do BAT ao final do tratamento, não havendo também alteração no conteúdo protéico desse tecido. 
O BAT exerce importante participação na regulação do gasto energético em roedores, através do desacoplamento da cadeia de transporte de elétrons nas mitocôndrias, responsável pela produção de ATP. Assim, a energia é dissipada na forma de calor. A proteína desacopladora 1 (UCP-1), presente exclusivamente no BAT, tem função fundamental neste processo, uma vez que atua como uma passagem alternativa para os prótons gerados durante a oxidação de substratos (Argyropoulos \& Harper, 2002; Erlanson-Albertsson, 2003).

Observamos que a reposição estrogênica causa aumento na expressão protéica de UCP-1 no BAT, o qual é potencializado pelo tratamento central com leptina. Pedersen e cols, em 2001, verificaram que a expressão do RNAm de UCP-1 em ratas castradas sem reposição estrogênica é significativamente menor do que em animais tratados. Além disso, a exposição de ratas intactas ao frio em diferentes fases do ciclo estral revelou que a expressão de RNAm de UCP-1 no BAT foi maior quando essas fêmeas estavam em proestro, e esse resultado se correlacionava com as concentrações plasmáticas de estradiol (Uchida et al., 2009). Foi demonstrado que fêmeas apresentam maior conteúdo de UCP-1 e que sua expressão é reduzida concomitantemente ao declínio da função reprodutiva e consequente redução nos níveis estrogênicos (Valle et al., 2008), o que está de acordo com nosso resultado de maior expressão de UCP-1 nas ratas tratadas com estradiol. Também, Masaki e cols, 2003, verificaram que a administração central de leptina causa aumento na expressão de RNAm de UCP-1 no BAT e redução na deposição de lipídeos nesse tecido em camundongos.

Quando realizamos a administração prévia de ASG ocorreu a inibição do aumento na expressão de UCP-1 promovido pela leptina nas ratas OVX+E. Sabe-se que o CRF participa na regulação do metabolismo energético. Além disso, 
foi demonstrado que a administração central de CRF causa aumento na atividade do sistema nervoso simpático no tecido adiposo marrom interescapular (IBAT) (Egawa et al., 1990). Correia e cols, 2001, utilizando ratos Sprague Dawley, verificaram que a ativação do SNA no IBAT causada pela administração central de leptina é parcialmente suprimida pela administração prévia de $\alpha-C R F$. Ainda, realizando-se a administração central de leptina, observou-se que ocorre um aumento na expressão do RNAm para UCP-1 no BAT de camundongos, o qual é parcialmente revertido com a infusão prévia de a-CRF (Masaki et al., 2003).

Observamos que o tratamento central com leptina levou ao aumento na ativação neuronal no $A R Q$ de fêmeas castradas com e sem reposição estrogênica. Contudo, uma vez que o número de neurônios com dupla marcação Fos e CART no $A R Q$ desses animais é semelhante, o cipionato de estradiol pode estar induzindo a ativação de outros neurônios anorexígenos desta região. Ao realizarmos o prétratamento com antagonista de CRF-R2 houve o bloqueio na ativação neuronal somente nas ratas que estavam recebendo a reposição hormonal. $O$ transcrito regulado por cocaína e anfetamina foi primariamente descrito como um peptídeo com aumento em sua transcrição em resposta à administração de cocaína ou anfetamina (Douglass et al., 1995). Posteriormente, foi descoberto que a injeção icv de CART inibe a ingestão alimentar (Kristensen et al., 1998; Lambert et al., 1998; Larsen et al., 2000). Em estudo de Elias e cols, 2001, foi mapeada a distribuição de neurônios CART em hipotálamo de rato, encontrados no PVN, SON, LHA, ARQ, DMH e PMV. Os neurônios CART presentes no ARQ aparentemente são regulados pela leptina, uma vez que eles expressam o RNAm para o receptor de leptina OBRb e são ativados após infusão endovenosa de leptina (Elias et al., 2001; Vrang, 2006). Kristensen e cols, 1998, demonstraram que a expressão do RNAm para CART no 
$A R Q$ é dependente da sinalização de leptina, uma vez que camundongos ob/ob (que apresentam deficiência de leptina funcional circulante) e ratos fa/fa (que apresentam defeito no receptor para leptina) apresentam redução na expressão de CART. Esses dados foram corroborados em diversos estudos posteriores (Ahima \& Hileman, 2000; Choi et al., 2004; Ambati et al., 2007). Foi demonstrado que após a ovariectomia há uma redução na expressão do RNAm para CART em hipotálamo de camundongas (Isken et al., 2008), sugerindo que os hormônios ovarianos modulam a expressão gênica de CART no hipotálamo.

Neurônios CART do ARQ ativados por leptina projetam-se a níveis superiores da coluna espinal. A injeção de traçadores retrógrados na coluna espinal demonstrou que as aferências de neurônios CART se originam no núcleo retroquiasmático e na região lateral do $A R Q$ (Elias et al., 1998). Sabe-se que essa região da coluna espinal possui neurônios pré-ganglionares simpáticos que inervam o BAT interescapular em roedores (Lowel \& Flier, 1997). Assim, a deficiência de leptina, em camundongos ob/ob leva à hiperfagia e à redução na temperatura corporal e no gasto energético (Pelleymounter et al., 1995). Dessa forma, em nosso modelo a maior expressão de UCP-1 no BAT pode ocorrer devido a uma ativação direta do SNS pela leptina ou por uma ativação indireta desse sistema devido à ativação de neurônios CART no $A R Q$ em resposta à leptina administrada centralmente.

Uma vez que nas fêmeas que receberam o antagonista de CRF-R2 houve inibição da hipofagia, da perda de peso, do aumento da expressão de UCP-1 e da ativação de neurônios do $A R Q$ em resposta ao estímulo pela leptina, demonstramos que o CRF possui importante participação na regulação da homeostase energética em fêmeas, possivelmente agindo como um mediador dos 
efeitos da leptina. Chen e cols, 2009, injetaram traçador retrógrado no ARQ de ratos e, por meio da combinação das técnicas de imunoistoquímica e hibridização in situ, demonstraram que os neurônios que expressam CRF-R2 no VMH enviam projeções diretas para o $A R Q$. Diversos estudos sugerem a participação do $\mathrm{VMH}$ no controle da termogênese do BAT, uma vez que a estimulação química ou elétrica deste núcleo causa alterações morfológicas e bioquímicas do IBAT, bem como alterações na taxa de disparos dos nervos que inervam essa região (Hogan et al., 1982; Holt et al., 1987; Amir, 1990). Ainda, utilizando a injeção de traçadores, Bamshad e cols, 1999, verificaram que o BAT recebe aferências da MPOA, PVN, VMH, LHA e RCA. Assim, acreditamos que o bloqueio de neurônios que expressam CRF-R2 pela ASG no $\mathrm{VMH}$ atenua a ativação neuronal do $A R Q$ e o aumento da expressão de UCP-1 induzidos pela leptina. 
6. SUMÁRIO E CONCLUSÕES 
Os dados obtidos em nosso trabalho demonstram que a reposição com cipionato de estradiol em ratas ovariectomizadas induz:

- Diminuição da ingestão alimentar e do ganho de peso corporal;

- Aumento das concentrações plasmáticas de corticosterona e leptina no estado pré-alimentar, bem como das concentrações plasmáticas de corticosterona em resposta à alimentação;

- Aumento da resposta hipofágica e de perda de peso corporal ao estímulo central com leptina, a qual é bloqueada com a administração prévia de um antagonista de CRF-R2;

- Aumento da expressão protéica de UCP-1 no tecido adiposo marrom, a qual é potencializada ao estímulo central com leptina, que por sua vez é bloqueada com a administração prévia de um antagonista de CRF-R2;

- Aumento da imunorreatividade de Fos no $A R Q$ induzida pelo estímulo central com leptina, a qual é bloqueada com a administração prévia de um antagonista de CRF-R2;

- Manutenção da imunorreatividade Fos/CART no ARQ induzida pelo estímulo central com leptina, a qual é bloqueada com a administração prévia de um antagonista de CRF-R2.

Dessa forma, sugerimos que o estradiol possui importante participação na regulação da homeostase energética, modulando a ingestão alimentar, o ganho de peso corporal e o gasto energético por meio da ativação da termogênese pelo tecido adiposo marrom. Ainda, que o estradiol aumenta a responsividade à ação hipofágica central da leptina, a qual é mediada, pelo menos em parte, pelo CRF, por meio de seus receptores tipo 2 . 
7. REFERÊNCIAS 
Abrantes, M. M.; Lamounier, A. J.; Colosimo, A. E. Overweight and obesity prevalence among children and adolescents from northeast regions of Brazil. Jornal de Pediatria, v. 78; n. 4; 2002.

Ahima, R. S.; Hileman, S. M. Postnatal regulation of hypothalamic neuropeptide expression by leptin: implications for energy balance and body weight regulation. Regulatory Peptides, v. 92, p. $1-7,2000$.

Alonso, A.; Fernández, R.; Moreno, M.; Ordóñez, P.; Díaz, F.; González, C. Leptin and Its Receptor Are Controlled by 17b-Estradiol in Peripheral Tissues of Ovariectomized Rats. Experimental Biology and Medicine, v. 232, p. 542 - 549, 2007.

Ambati, S.; Duan, J.; Duff, E.; Choi, Y-H.; Hartzell, D. L.; Della-Fera, M. A.; Baile, C. A. Gene expression in arcuate nucleus-median eminence of rats treated with leptin or ciliary neurotrophic factor. BioFactors, v. 31, p. 133 - 144, 2007.

Amir, S. Intra-ventromedial hypothalamic injection of glutamate stimulates brown adipose tissue thermogenesis in the rat. Brain Research, v. 511, p. 341-344, 1990.

Anand, B.K.; Brobeck, J.R. Localization of a "feeding center" in the hyphotalamus of the rat. Proceedings of the Society for Experimental Biology and Medicine, v.77, p.323-324, 1951.

Asarian, Lori; Geary, Nori. Cyclic estradiol treatment normalizes body weight and restores physiological patterns of spontaneous feeding and sexual receptivity in ovariectomized rats. Hormones and Behavior, v. 42, p. $461-471,2002$.

Asarian, L.; Geary, N. Modulation of appetite by gonadal steroid hormones. Philosophical Transactions of the Royal Society B, v. 361, p. $1251-1263,2006$.

Arase, K.; York, D.A.; Shimizu, H.; Shargill, N.; Bray, G.A. Effects of corticotropinreleasing factor on food intake and brown adiopose tissue thermogenesis in rats. American Journal Physiology, v. 255, p. E255-E259, 1988.

Argyropoulos, G.; Harper, M-E. Molecular Biology of Thermoregulation Invited Review: Uncoupling proteins and thermoregulation. Journal of Applied Physiology, v. 92, p. $2187-2198,2002$. 
Arora, S.; Anubhuti. Role of neuropeptides in appetite regulation and obesity - A review. Neuropeptides, v. 40, p. $375-401,2006$.

Asarian, Lori; geary, Nori. Modulation of appetite by gonadal steroid hormones. Philosophical Transactions of The Royal Society, v. 361, 2006. p. $1251-1263$.

Badman, M. K.; Flier, J. S. The adipocyte as an active participant in energy balance and metabolism. Gastroenterology, v. 132, p. 2103 - 2115, 2007.

Bado A, Levasseur S, Attoub S, Kermorgant S, Laigneau JP, Bortoluzzi MN, Moizo L, Lehy T, Guerre-Millo M, Le Marchand-Brustel Y, Lewin MJ. The stomach is a source of leptin. Nature, v. 394, p. 790 - 793, 1998.

Bamshad, M.; Song, K.; Bartness, T. J. CNS origins of the sympathetic nervous system outflow to brown adipose tissue. American Journal of Physiology Regulatory, Integrative and Comparative Physiology, v. 276, p. 1569 - 1578, 1999.

Bartness, Timothy J.; Wade, George N. Effects of interscapular brown adipose tissue denervation on body weight and energy metabolism in ovariectomized and estradioltreated rats. Behavioral Neuroscience, 98, n. 4, p. $674-685,1984$.

Becker, D.J., Ongemba, L.N., Brichard, V., Henquin, J.C., Brichard, S.M. Diet- and diabetes-induced changes of ob gene expression in rat adipose tissue. FEBS Lett, v. 371, p. 324 - 328, 1995.

Belda, Xavier et al. The effects of chronic food restriction on hypothalamic-pituitaryadrenal activity depend on morning versus evening availability of food. Pharmacology, Biochemistry and Behavior, v. 81, p. 41 - 46, 2005.

Berthoud, H-R. Multiple neural systems controlling food intake and body weight. Neuroscience and Biobehavioral Reviews, v. 26, p. $393-428,2002$.

Berthoud, H-R; Morrison, C. The brain, appetite and obesity. Annual Review of Psychology, v. 59, p. $55-92,2008$. 
Blaustein, J.D.; Wade, G.N. Ovarian influences on the meal patterns of female rats. Physiology and Behavior, v. 17, p. $201-208,1976$.

Brann, D. W.; Sevilla, L.; Zamorano, P. L.; Mahesh, V. B. Regulation of leptin gene expression and secretion by steroid hormones. Steroids, v. 64, p. 659 - 663, 1999.

Bray, G.A.; Fisher, J.; York, D.A. Neuroendocrinecontrol of the development of obesity: understanding gained from studies of experimental animal models. Frontiers in Neuroendocrinology, v.11, p.128-181, 1990.

Brown, M. R.; Fisher, L. A. Corticotropin-releasing factor: effects on the autonomic nervous system and visceral systems. Fed Proc., v. 44, p. 243-248, 1985.

Butera, P.C.; Xiong, M.; Davis, R.J.; Platania, S.P. Central implants of dilute estradiol enhance the satiety effect of CCK-8. Behavioral Neuroscience, v. 110, p. $823-$ 830, 1996.

Cai, X.J.; Widdowson, P.S.; Harrold, J.; Wilson, S.; Buckinggham, R.E.; Arch, J.R.S. Hypothalamic orexin expression-modulation by blood glucose and feeding. Diabetes, v.14, p.2132-2137, 1999.

Campfield LA, Smith FJ, Guisez Y, Devos R, Burn P. Recombinant mouse OB protein: evidence for a peripheral signal linking adiposity and central neural networks. Science, v. 269, p. $546-549,1995$.

Chalmers, D.T.; Lovenberg, T. W.; De Souza, E. B. Localization of Novel Corticotropin-Releasing Factor Receptor $\left(\mathrm{CRF}_{2}\right)$ mRNA Expression to Specific Subcortical Nuclei in Rat Brain: Comparison with $\mathrm{CRF}_{1}$ Receptor mRNA Expression. The Journal of Neuroscience, v. 15, n. 10, p. $6340-6350,1995$.

Chen, P.; Vaughan, J.; Donaldson, C.; Vale, W.; Li, C. Injection of urocortin 3 into the ventromedial hypothalamus modulates feeding, blood glucose levels, and hypothalamic POMC gene expression but not the HPA axis. American Journal of Physiology, Endocrinology and Metabolism, v. 298, p. 337 - 345, 2010.

Choi, Y-H.; Della-Fera, M. A.; Li, C.; Hartzell, D. L.; Little, D. E.; Kuhar, M. J.; Bail, C. A. CART peptide: central mediator of leptin-induced adipose tissue apoptosis? Regulatory Peptides, v. 121, p. 155 - 162, 2004. 
Chua SC Jr, Koutras IK, Han L, Liu SM, Kay J, Young SJ, Chung WK, Leibel RL. Fine structure of the murine leptin receptor gene: splice site suppression is required to form two alternatively spliced transcripts. Genomics, v. 45, p. 264 - 270, 1997.

Clegg, D. J.; Brown, L. M.; Woods, S. C.; Benoit, S. C. Gonadal hormones determine sensitivity to central leptin and insulin. Diabetes, v. 55, n. 4, p. 978-987, 2006.

Considine, R.V.; Sinha, M.K.; Heiman, M.L.; Kriauciunas, A.; Stephens, T.W.; Nyce, M.R. Serum immunoreactive-leptin concentrations in normal-weight and obese humans. The New England Journal of Medicine, v. 334, p. 292 - 295, 1996.

Contarino, A.; Dellu, F.; Koob, G. F.; Smith, G. W.; Lee, K.; Vale, W. W.; Gold, L. H. Dissociation of locomotor activation and suppression of food intake induced by CRF in CRFR1-deficient mice. Endocrinology, v. 141, p. 2698 - 2702, 2000.

Correia, M. L. G.; Morgan, D. A.; Mitchell, J. L.; Sivitz, W. I.; Mark, A. L.; Haynes, W. G. Role of Corticotrophin-Releasing Factor in Effects of Leptin on Sympathetic Nerve Activity and Arterial Pressure. Hypertension, v. 38, p. $384-388,2001$.

Couceyro, P. R.; Koylu, E. O.; Kuhar, M. J. Further studies on the anatomical distribution of CART by in situ hybridization. Journal of Chemical Neuroanatomy., v. 12, n. 4, p. 229-241, 1997.

Cowley, M.A.; Smart, J.L; Rubinstein, M.; Cerdan, M.G; Diano, S.; Horvath, T.L. Leptin activates anorexigenic POMC neurons through a neural network in the arcuate nucleus. Nature, v.411, p.480-484, 2001.

Cullen, M. J.; Ling, N.; Foster, A.C.; Pelleymounter, M. A. Urocortin, Corticotropin Releasing Factor-2 Receptors and Energy Balance. Endocrinology, v. 142, n. 3, p. $992-999,2001$.

Curtis, Kathleen S. Estrogen and the central control of body fluid balance. Physiology \& Behavior, v. 97, p. 180 - 192, 2009. 
Cypess AM, Lehman S, Williams G, Tal I, Rodman D, Goldfine AB, Kuo FC, Palmer EL, Tseng YH, Doria A, Kolodny GM, Kahn CR. Identification and importance of brown adipose tissue in adult humans. The New England Journal of Medicine, v. 360, p. $1509-1517,2009$.

Date, Y.; Ueta, Y.; Yamashita, H.; Yamaguchi, H.; Matsukura, S.; Kangawa, K. Orexins, orexigenic hypothalamic peptides, interact with autonomic, neuroendocrine and neuroregulatory systems. Proceedings of the National Academy of Sciences USA, v.96, p.748-753, 1999.

Del Bianco-Borges, B.; Cabral, F. J.; Franci, C. R. Co-expression of leptin and oestrogen receptors in the preoptic-hypothalamic area. Journal of Neuroendocrinology, v. 22, p. $996-1003,2010$.

Delecea, L.; Kilduff, T.S.; Peyron, C.; Gao, X.B.; Foye, P.E.; Danielson, P.E.; Fukuhara, C. e cols. The hypocretins-hypothalamus-specific peptides with neuroexcitatory activity. Proceedings of the National Academy of Sciences USA, v.95, p.322-327, 1998.

Demerath, E.W.; Towne, B.; Wisemandle, W.; Blangero, J.; Chumlea, W.C.; Siervogel, R.M. Serum leptin concentration, body composition, gonadal hormones during puberty. International Journal of Obesity and Related Metabolic Disorders, v. 23, p. $678-685,1999$.

Diano, S.; Kalra, S.P.; Sakamoto, H.; Horvath, T.L. Leptin receptors in estrogen receptor-containing neurons of the female rat hypothalamus. Brain Research, v. 812, p. 256 - 259, 1998.

Douglass, J.; McKinzie, A. A.; Couceyro, P. PCR differential display identifies a rat brain mRNA that is transcriptionally regulated by cocaine and amphetamine. The Journal of Neuroscience, v. 15, n. 3, p. 2471 - 2481, 1995.

Dye, L.; Blundell, J.E. Menstrual cycle and appetite control: implications for weight regulation. Human Reproduction, v.12, p.1142-1151, 1997.

Eckel, L.A.; Geary, N. Estradiol treatment increases feeding-induced c-fos expression in the brains of ovariectomized rats. American Journal of Physiology, v. 281, p. $738-746,2001$. 
Eckel, L.A.; Houpt, T.A.; Geary, N. Estradiol replacement increases CCK-induced cfos expression in the brains of ovariectomized rats. American Journal of Physiology, v.283, p.R1378-R1385, 2002.

Eckel, L.A.; Houpt, T.A.; Geary, N. Spontaneous meal patterns in female rats with and without access to running wheels. Physiology and Behavior, v.70, p.397-405, 2000.

Egawa, M.; Yoshimatsu, H.; Bray, G. A. Effect of corticotropin releasing hormone and neuropeptide $\mathrm{Y}$ on electrophysiological activity of sympathetic nerves to interscapular brown adipose tissue. Neuroscience, v. 34, n. 3, p. $771-775,1990$.

Elias, C. F.; Lee, C.; Kelly, J.; Aschkenasi, C.; Ahima, R. S.; Couceyro, P. R.; Kuhar, M. J.; Saper, C. B.; Elmquist, J. K. Leptin activates hypothalamic CART neurons projecting to the spinal cord. Neuron, v. 21, p. $1375-1385,1998$.

Elias, C.F.; Aschkenasi, C.; Lee, C.; Kelly, J.; Ahima, R.S.; Bjorbaek, C.; Flier, J.S., Saper, C.B.; Elmquist, J.K. Leptin differentially regulates NPY and POMC neurons projecting to the lateral hypothalamic area. Neuron, v. 23, p. $775-786,1999$.

Elias, C. F.; Lee, C. E.; Kelly, J. F.; Ahima, R. S.; Kuhar, M.; Saper, C. B.; Elmquist, J. K. Characterization of CART neurons in the rat and human hypothalamus. The Journal Of Comparative Neurology, v. 432, p.1 - 19, 2001.

Elmquist, J.; Bjorbaek,C.; Ahima, R.S.; Flier, J.S.; Saper, C.B. Distributions of leptin receptor mRNA isoforms in the rat brain. Comparative Journal of Neurology, v. 395, p.535-547, 1998.

Elmquist, J.; Elias, C.F.; Saper, C.B. From lesions to leptin: hypotalamic control of food intake and body weight. Neuron, v.22, p.221-232, 1999.

Enerbäck S, Jacobsson A, Simpson EM, Guerra C, Yamashita H, Harper ME, Kozak LP. Mice lacking mitochondrial uncoupling protein are cold-sensitive but not obese. Nature, v. 387, p. 90 - 94, 1997. 
Erlanson - Albertsson, C. The role of uncoupling proteins in the regulation of metabolism. Acta Physiologica Scandinavica, v. 178, p. 405 - 412, 2003.

Fei, H.; Okano, H.J.; Li, C.; Lee, G.H.; Zhao, C.; Darnell, R.; Friedman, J.M. Anatomic localization of alternatively spliced leptin receptors $(\mathrm{Ob}-\mathrm{R})$ in mouse brain and other tissues. Proceedings of the National Academy of Sciences USA, v.94, p.7001-7005, 1997.

Frederich RC, Hamann A, Anderson S, Löllmann B, Lowell BB, Flier JS. Leptin levels reflect body lipid content in mice: evidence for diet-induced resistance to leptin action. Nature Medicine, v. 1, p. 1311 - 1314, 1995.

Gardner, J. D.; Rothwell, N. J.; Luheshi, G. N. Leptin affects food intake via CRFreceptormediated pathways. Nature Neuroscience, v. 1, n. 2, p. 103, 1998.

Gautvik, K. M.; de Lecea, L.; Gautvik, V. T.; Danielson, P. E.; Tranque, P.; Dopazo, A.; Bloom, F. E.; Sutcliffe, J. G. Overview of the most prevalent hypothalamusspecific mRNAs, as identified by directional tag PCR subtraction. Proceedings of the National Academy of Sciences USA, v. 93, n. 16, p. 8733-8738, 1996.

Geary, Nori et al. Deficits in E2-dependent control of feeding, weight gain, and cholecystokinin satiation in ER-null mice. Endocrinology, v. 142, n. 11, p. 4751 4757, 2001.

Gómez-Ambrosi J, Frühbeck G, Martínez JA. Leptin, but not a beta 3-adrenergic agonist, upregulates muscle uncoupling protein-3 messenger RNA expression: shortterm thermogenic interactions. Cellular and Molecular Life Sciences, v. 55, p. 992 $-997,1999$.

Gortari, P.; Mancera, K.; Cote-Vélez, A.; Amaya, M.I.; Martínez, A.; Jaimes-Hoy, L.; Joseph-Bravo, P. Involvement of CRH-R2 receptor in Ealing behavior and in the response of the HPT axis in rats subjected to dehydration-induced anorexia. Psychoneuroendocrinology, v. 34, n. 2, p. 259-272, 2009.

Gray, J.M.; Wade, G.N. Food intake, body weight and adiposity in female rats: actions and interactions of progestins and antiestrogens. American Journal Physiology, v. 240, p. $474-481,1981$. 
Green, W.P.; Greene, G.; Krust, A.; Bornert, J.M.; Jeltsch, J.M.; Staub, A. Clonig of the human estrogen gene. Proceedings of the National Academy of Sciences USA, v. 82, p. 7889 - 7893, 1985.

Hahn, T.; Breininger, J.; Baskin, D.; Schwartz, M. Coexpression of Agrp and NPY in fasting-activated hypothalamic neurons. Nature Neuroscience, v.1, p.271-272, 1998.

Hakanson, M.L.; Brown, H.; Ghilardi, N.; Skoda, R.C.; Meister, B. Leptin receptor immunoreactivity in chemically defined target neurons of the hipotalamus. Journal of Neuroscience, v. 18, p. $559-572,1998$.

Hardie, L.J.; Rayner, D.V.; Holmes, S.; Trayhurn, P. Circulating leptin levels are modulated by fasting, cold exposure and insulin administration in lean but not Zucker (fa/fa) rats a measured by ELISA. Biochemical and Biophysical Research Communications, vol.223, p.660-665, 1996.

Hauger, R. L.; Grigoriadis, D. E.; Dallman, M. F.; Plotsky, P. M.; Vale, W. W.; Dautzenberg, F. M. International Union of Pharmacology. XXXVI. Current status of the nomenclature for receptors for corticotropin-releasing factor and their ligands. Pharmacological Reviews, v. 55, n. 1, p. 21 - 26, 2003.

Havel, P. J. Role of adipose tissue in body-weight regulation: mechanisms regulating leptin production and energy balance. Proceedings of the Nutrition Society, v. 59, p. $359-371,2000$.

Haynes, W.G.; Morgan, D.A.; Walsh, S.A.; Mark, A.L.; Sivitz, W.I. Receptor-mediated regional sympathetic nerve activation by leptin. Journal of Clinical Investigation, v.100, p.270-278, 1997.

Heinrichs, S. C.; Lapsansky, J.; Behan, D. P.; Chan, R. K.; Sawchenko, P. E.; Lorang, M.; Ling, N.; Vale, W. W.; de Souza, E. B. Corticotropin-releasing factorbinding protein ligand inhibitor blunts excessive weight gain in genetically obese Zucker rats and rats during nicotine withdrawal. Proceedings of the National Academy of Sciences USA, v. 93, n. 26, p. 15475-15480, 1996. 
Hermanussen, M.; García, A.P.; Sunder, M.; Voigt, M.; Salazar, V.; Tresguerres, J.A.F. Obesity, voracity, and short stature: the impact of glutamate on the regulation of appetite. European Journal of Clinical Nutrition, v. 60, p. $25-31,2006$.

Herzog, Erik D.; Schwartz, William, J. Functional genomics of sleep and circadian rhythm Invited review: A neural clockwork for encoding circadian time. Jounal of Applied Physiology, v. 92, p. $401-408,2002$.

Hetherington, A.W.; Ranson, S.W. Hypothalamic lesions and adiposity in the rat. Anat Rec, v.78, p.149-172, 1940.

Hogan, S.; Coscina, D. V.;Himms-Hagen, J. Brown adipose tissue of rats with obesity-inducing ventromedial hypothalamic lesions. American Journal of Physiology, v. 243, p. 338 - 344, 1982.

Holt, S. J.; Wheal, H. V.;York, D. A. Hypothalamic control of brown adipose tissue in Zucker lean and obese rats: effect of electrical stimulation of the ventromedial nucleus and other hypothalamic centres. Brain Research, v. 405, p. $227-233$, 1987.

Huang, Q.; Rivest, R.; Richard, D. Effects of leptin on corticotrophin-releasing factor (CRF) synthesis and CRF neuron activation in the paraventricular hypothalamic nucleus of obese (ob/ob) mice. Endocrinology, v.139, p.1524-1532, 1998.

Iguchi M, Aiba S, Yoshino Y, Tagami H. Human follicular papilla cells carry out nonadipose tissue production of leptin. Journal of Investigative Dermatology, v. 117, p. 1349 - 1356, 2001.

Isken, F.; Pfeiffer, A. F. H.; Nogueiras, R.; Osterhoff, M. A.; Ristow, M.; Thores, B.; Tscho, M. H.; Weickert, M. O. Deficiency of glucose-dependent insulinotropic polypeptide receptor prevents ovariectomy-induced obesity in mice. American Journal of Physiology, Endocrinololy and Metabolism, v. 295, p. E350-E355, 2008.

Kemnitz, Joseph W. Ovarian hormones influence brown adipose tissue. Pharmacology, Biochemistry and Behavior, v. 18, p. 563 - 566, 1983. 
Kemnitz, J.W.; Gibber, J.R.; Lindsay, K.A.; Eisele, S.G. Effects of ovarian hormones on eating behaviors, body weight, and glucoregulation in rhesus monkeys. Hormones and Behavior, v. 23, p. $235-250,1989$.

Khor, V. K.; Dhir, R.; Yin, X.; Ahima, R. S.; Song, W-C. Estrogen sulfotransferase regulates body fat and glucose homeostasis in female mice. American Journal of Physioliogy, Endocrinology and Metabolism, v. 299, p. 657 - 664, 2010.

Krahn, D.D.; Gosnell, B. A.; Majchrzak, M. J. The anorectic effects of CRH and restraint stress decrease with repeated exposures. Biological Psychiatry, v. 27, p. $1094-1102,1990$.

Krause, Eric G. et al. Estrogen influences stimulated water intake by ovariectomized female rats. Physiology \& Behavior, v. 79, 2003. p. $267-274$.

Kristensen, P.; Judge, M.; Thim, L; Riebel, U.; Christjansen, K.N.; Wullf, B.B.; Clausen, J.T.; Jensen, P.B.; Madsen, O.D.; Vrang, N.; Larsen, P.J.; Hastrup, S. Hypothalamic CART is a new anoretic peptide regulated by leptin. Nature, v. 393, p. 72-76, 1998.

Kuhar, M. J.; Dall Vechia, S. E. CART peptides: novel addiction- and feeding-related neuropeptides. Trends in Neurosciences., v. 22, n. 7, p. 316-320, 1999.

Kuiper, G.G.; Enmark, E.; Pelto-Huikko, M.; Nilsson, S.; Gustafsson, J.A. Clonig of a novel receptor expressed in rat prostate and ovary. Proceedings of the National Academy of Sciences USA, v. 93, p. 5925 - 5930, 1996.

Laflamme, N.; Nappi, R. E.; Drolet, G.; Labrie, C.; Rivest, S. Expression and neuropeptidergic characterization of estrogen receptors (ER $\alpha$ and $E R \beta$ ) throughout the rat brain: anatomical evidence of distinct roles of each subtype. Journal of Neurobiology, v. 36, p. $357-378,1998$.

Lambert, P. D.; Couceyro, P. R.; McGirr, K. M.; Dall Vechia, S. E.; Smith, Y.; Kuhar, M. J. CART peptides in the central control of feeding and interactions with neuropeptide Y. Synapse, v. 29, p. $293-298,1998$.

Landau, T.; Zucker, I. Estrogenic regulation of body weight in the female rat. Hormonal Behavior, v. 7, p. 29 - 39, 1976. 
Larsen, P. J.; Vrang, N.; Petersen, P. C.; Kristensen, P. Chronic intracerebroventricular administration of recombinant CART (42-89) peptide inhibits and causes weight loss in lean and obese Zucker (fa/fa) rats. Obesity Research., v. 8, n. 8, p. 590-596, 2000.

Lean M.E. Brown adipose tissue in humans. Proceedings of the Nutrition Society, v. 48 , p. $243-256,1989$.

Lee, G.H.; Proenca, R.; Montez, J.M.; Carroll, K.M.; Darvishzadeh, J.G.; Lee, J.J. Abnormal splicing of the leptin receptor in diabetic mice. Nature, v.37, p.632-635, 1996.

Lee, P.; Greenfield, J. R.; Ho, K. K. Y.; Fulham, M. J. A critical appraisal of the prevalence and metabolic significance of brown adipose tissue in adult humans. American Journal of Physiology, Endocrinology and Metabolism, v. 299, p. 601 $-606,2010$.

Leshner, A.I.; Collier, G. The effects of gonadectomy on the sex differences in dietary self-selection patterns and carcass composition of rats. Physiology Behavior, v.11, p.671-676, 1973.

Levin, B.E. Developmental gene $x$ environment interactions affecting systems regulating energy homeostasis and obesity. Frontiers in Neuroendocrinology, v. 31 , p. $270-283,2010$.

Lo, M-J.; Chang, L-L.; Wang, P. S. Effects of Estradiol on Corticosterone Secretion in Ovariectomized Rats. Journal of Cellular Biochemistry, v. 77, p. $560-568,2000$.

Lowel, B. B.; Flier, J. S. Brown adipose tissue, $\beta 3$-Adrenergic receptors, and obesity. Annual Review of Medicine, v. 48, p. 307 - 316, 1997.

Ludwig, D.S.; Tritos, N.A.; Mastaitis, J.W.; Kulkarni, R.; Kokkotou, E.; Elmquist, J. Melanin-concentrating hormone overexpression in transgenic mice leads to obesity and insulin resistance. Journal Clinical Investigation, v.107, 379-386, 2001. 
Machinal, F.; Dieudonne, M.N.; Leneveu, M.C.; Pecquery, R.; Giudicelli, Y. In vivo and in vitro ob gene expression and leptin secretion in rat adipocytes: evidence for a regional specific regulation by sex steroid hormones. Endocrinology, v. 140, p. 1567 - 1574, 1999.

Maffei M, Halaas J, Ravussin E, Pratley RE, Lee GH, Zhang Y, Fei H, Kim S, Lallone $\mathrm{R}$, Ranganathan $\mathrm{S}$, et al. Leptin levels in human and rodent: measurement of plasma leptin and ob RNA in obese and weight-reduced subjects. Nature Medicine, v. 1, p. 1155 - 1161, 1995.

Mancini, M. C.; Halpern, A. Tratamento Farmacológico da Obesidade. Arquivos Brasileiros de Endocrinologia e Metabologia, v. 46, n. 5, p. 497 - 512, 2002.

Martinez, V.; Barquist, E.; Rivier, J.; Taché, Y. Central CRF inhibits gastric emptying of a nutrient solid meal in rats: the role of CRF2 receptors. American Journal of Physiology - Gastrointestinal and Liver Physiology, n. 274, p. 965 - 970, 1998.

Masaki, T.; Yoshimichi, G.; Chiba, S.; Yasuda, T.; Noguchi, H.; Kakuma, T.; Sakata, T.; Yoshimatsu, H. Corticotropin-Releasing Hormone-Mediated Pathway of Leptin to Regulate Feeding, Adiposity, and Uncoupling Protein Expression in Mice. Endocrinology, v. 144, n. 8, p. 3547 - 3554, 2003.

Masuzaki H, Ogawa Y, Sagawa N, Hosoda K, Matsumoto T, Mise H, Nishimura H, Yoshimasa Y, Tanaka I, Mori T, Nakao K. Nonadipose tissue production of leptin: leptin as a novel placenta-derived hormone in humans. Nature Medicine, v. 3, p. 1029 - 1033, 1997.

Matyskova, R.; Zelezna, B.; Maixnerova, J.; Koutova, D.; Haluzik, M.; Maletinska, L. Estradiol supplementation helps overcome central leptin resistance of ovariectomized mice on a high fat diet. Hormone and Metabolic Research, v. 42, p. $182-186$, 2010.

Meister, B. Neurotransmitters in key neurons of the hypothalamus that regulate feeding behavior and body weight. Physiology \& Behavior, v.92(1-2), p.263-271, 2007.

Mook, D.G.; Kenney, N.J.; Roberts, S.; Nussbaum, A.I.; Rodier W.I. Ovarian-adrenal interactions in regulation of body weight by female rats. Journal Comparative Physiological Psychology, v.81, p.198-211, 1972. 
Morley, J. E.; Levine, A. S. The role of the endogenous opiates as regulators of appetite. The American Journal of Clinical Nutrition., v. 35, n. 4, p. 757-761, 1982.

Mountjoy, K. G. Functions for pro-opiomelanocortin-derived peptides in obesity and diabetes. Biochemical Journal, v. 428, p. $305-324,2010$.

Mueller, K, Hsiao S. Estrus- and ovariectomy-induced body weight changes: evidence for two estrogenic mechanisms. Journal of Comparative and Physiological Psychology, v. 94, p. 1126 - 1134, 1980.

Nedergaard, J.; Cannon, B. The Changed Metabolic World with Human Brown Adipose Tissue:Therapeutic Visions. Cell Metabolism, v. 11, p. 268 - 272, 2010.

Nicholls, D. G.; Snelling, R.; Rial, E. Proton and calcium circuits across the mitochondrial inner membrane. Biochemical Society Transactions., v. 12, n. 3, p. 388-390, 1984.

Pedersen, Steen B. et al. Regulation of UCP1, UCP2, and UCP3 mRNA expression in brown adipose tissue, white adipose tissue, and skeletal muscle in rats by estrogen. Biochemical and Biophysical Research Communications, v. 288, p. $191-197,2001$.

Peixoto, M. R. G.; Benício, M. H. D.; Veiga J., Brandão, P. C. The relationship between body mass index and lifestyle in a Brazilian adult population: a crosssectional survey. Caderno de Saúde Pública, Rio de Janeiro, v. 23, n. 11, p. 2694 2704, 2007.

Pelletier, G.; Li, S.; Luu-The, V.; Labrie, F. Oestrogenic regulation of propiomelanocortin, neuropeptide $Y$ and corticotrophin-releasing hormone mRNAs in mouse hypothalamus. Journal of Neuroendocrinology., v. 19, n. 6, p. 426-431, 2007.

Pelleymounter MA, Cullen MJ, Baker MB, Hecht R, Winters D, Boone T, Collins F. Effects of the obese gene product on body weight regulation in ob/ob mice. Science, v. 269 , p. $540-543,1995$. 
Qu, D.; Ludwig, D.S.; Gammeltoft, S.; Piper, M.; Pelleymounter, M.A.; Cullen, M.J. A role for melanin-concentrating hormone in the central regulation of feeding behavior. Nature, v.380, p.243-247, 1996.

Remesar, X.; Fernández-López, J. A.; Blay, M. T.; Savall, P.; Salas, A.; Díaz-Silva, M.; Esteve, M.; Grasa, M. M.; Alemany, M. Effect of oral oleoyl-estrone on adipose tissue composition in male rats. International Journal of Obesity, v. 26, p. 1092 1102, 2002.

Reseland JE, Syversen U, Bakke I, Qvigstad G, Eide LG, Hjertner O, Gordeladze JO, Drevon CA. Leptin is expressed in and secreted from primary cultures of human osteoblasts and promotes bone mineralization. Journal of Bone and Mineral Research, v. 16, p. 1426 - 1433, 2001.

Ricquier D, Bouillaud F. Mitochondrial uncoupling proteins: from mitochondria to the regulation of energy balance. Journal of Physiology, v. 529, p. 3-10, 2000.

Robaczyk, M.; Smiarowska, M.; Krzyzanowska-Swiniarska, B. The ob gene product (leptin)-a new hormone of adipose tissue. Przegl Lek, v.54(5), p.348-352, 1997.

Rocha, M.; Bing, C.; Williams, G.; Puerta, M. Physiologic estradiol levels enhance hypothalamic expression of the long form of the leptin receptor in intact rats. Journal of Nutritional Biochemistry, v. 15, p. $328-334,2004$.

Roesch, Darren M. Effects of selective estrogen receptor agonists on food intake and body weight gain in rats. Physiology \& Behavior, v. 87, p. $39-44,2005$.

Rohner-Jeanrenaud, F.; Walker, C. D.; Greco-Perotto, R.; Jeanrenaud, B. Central corticotrophin-releasing factor administration prevents the excessive body weight gain of genetically obese (fa/fa) rats. Endocrinology, v. 124, n. 2, p. 733-739, 1989.

Salas, Anna et al. Rats treated with oleoyl-oestrone maintain glucidic homeostasis: comparisons with a pair-fed model. British Journal of Nutrition, v.94, p. $738-745$, 2005. 
Santollo, Jessica et al. Acute activation of ERa decreases food intake, meal size, and body weight in ovariectomized rats. American Journal of Physiology, Regulatory, Integrative and Comparative Physiology, v. 293, p. 2194 - 2201, 2007.

Sawchenko, P.E. Toward a new neurobiology of energy balance, appetite, and obesity: the anatomists weigh in. Journal of Comparative Neurology, v. 402(4), p.435-441, 1998.

Schwartz, M.W.; Baskin, D.G.; Bukowski, T.R.; Kuijper, J.L.; Foster, D.; Lasser, G.; Prunkard, D.E.; Porte, D. JR.; Woods, S.C.; Seeley, R.J.; Weigle, D.S. Specificity of leptin action on elevated blood glucose levels and hypothalamic neuropeptide $\mathrm{Y}$ gene expression in ob/ob mice. Diabetes, v. 45, p. 531 - 535, 1996.

Schwartz, M.W.et al. Leptin increase hypotalamic proopiomelanocortin (POMC) mRNA expression in the rostral arcuate nucleus. Diabetes, v. 46, p. $2119-2123$, 1997.

Schwartz, M.W.; Woods, S.C.; Porte, Jr.D.; Seeley, R.J.; Baskin, D.G. Central nervous system control of food intake. Nature, v.404, p.661-671, 2000.

Sell, H.; Deshaies, Y.; Richard, D. The brown adipocyte: update on its metabolic role. The International Journal of Biochemistry and Cell Biology, v. 36, p. 2098 2104, 2004.

Shimizu, H.; Shimomura, Y.; Nakanishi, Y.; Futawatari, T.; Ohtani, K.; Sato, N.; Mori, $M$. Estrogen increases in vivo leptin production in rats and human subjects. Journal of Endocrinology, v. 154, p. 285 - 292, 1997.

Shughrue, Paul J. et al. Comparative distribution of estrogen receptor- $\alpha$ and $-\beta$ mRNA in the rat central nervous system. The Journal of Comparative Neurology, v. 388, p. $507-525,1997$.

Silva, L. E. C. M.; Castro, M.; Amaral, F. C.; Antunes-Rodrigues, J.; Elias, L. L. K. Estradiol-induced hypophagia is associated with the differential mRNA expression of hypothalamic neuropeptides. Brazilian Journal of Medical and Biological Research, v. 43, n. 8, p. $759-766,2010$. 
Simerly, R. B.; Chang, C.; Muramatsu, M.; Swanson, L. W. Distribution of androgen and estrogen receptor mRNA-containing cells in the rat brain: an in situ hybridization study. The Journal of Comparative Neurology, v. 294, p. 76-95, 1990.

Smith RE. Thermogenic activity of the hibernating gland in the cold-acclimated rat. Physiologist, v. 4, p. 113, 1961.

Smith, A.I.; Funder, J.W. Proopiomelanocortin processing in the pituitary, central nervous system, and peripheral tissues. Endocrine Reviews, v. 9, p.159-179, 1988.

Stellar, E. The physiology of motivation. Psychological Review, v.101, p.301-311, 1954.

Stephens, T.W.; Basinski, M.; Bristow, P.K.; Bue-Valleskey, J.M.; Burgett, S.G.; Craft, L.; Hale, J.; Hoffmann, J.; Hsiung, H.M.; Kriauciunas, A. The role of neuropeptide $Y$ in the antiobesity action of the obese gene product. Nature, v. 377 p. $530-532,1995$.

Strubbe, Jan H.; Woods, Stephen C. The timing of meals. Psychological Review, v. 111, n. 1, p. $128-141,2004$.

Swanson LW, Sawchenko PE..Hypothalamic integration: organization of the paraventricular and supraoptic nuclei. Annual Reviews of Neuroscience, n. 6, p. $269-324,1983$.

Tabarin, A.; Diz-Chaves, Y.; Consoli, D.; Monsaingeon, M.; Bale, T. L.; Culler, M. D.; Datta, R.; Drago, F.; Vale, W. W.; Koob, G. F.; Zorrila, E. P.; Contarino, A. Role of the corticotropin-releasing factor receptor type 2 in the control of food intake in mice: a meal pattern analysis. European Journal of Neuroscience, v. 26, p. $2303-2314$, 2007.

Tammacharoen, Sumpun et al. Hindbrain administration of estradiol inhibits feeding and activates estrogen receptor- $\alpha$-expressing cells in the nucleus tractus solitarius of ovariectomized rats. Endocrinology, v. 149, n. 4, p. 1609 - 1617, 2008. 
Tan, D. X.; Manchester, L. C.; Fuentes-Broto, L.; Paredes, S. D.; Reiter, R. J. Significance and application of melatonin in the regulation of brown adipose tissue metabolism: relation to human obesity.Obesity Reviews, p. 1 - 22, 2010.

Tartaglia LA. The leptin receptor. The Journal of Biological Chemistry, v. 272, p. 6093 - 6096, 1997.

Tarttelin, M.F.; Gorski, R.A. The effects of the ovarian steroids on food and water intake and body weight in the female rat. Acta Endocrinologica, v.72, p.551-568, 1973.

Thornton, J.; Cheng, C.; Clifton, D.; Steiner, R. Reglation of hypothalamic proopiomelanocortin mRNA by leptin in ob/ob mice. Endocrinology, v.138, p.5063 5066, 1997.

Toth, Michael J. et al. Effects of estradiol and progesterone on body composition, protein synthesis, and lipoprotein lipase in rats. American Journal of Physiology, Endocrinology and Metabolism, v. 280, p. 496 - 501, 2001.

Trayhurn P, Thomas ME, Duncan JS, Rayner DV. Effects of fasting and refeeding on ob gene expression in white adipose tissue of lean and obese (oblob) mice. FEBS Lett, v. 368, p. 488 - 490, 1995.

Tritos, N.A.; Vicent, D.; Gillette, J.; Ludwig, D.S.; Flier, E.S.; Maratos-Flier, E. Functional interactions between melanin-concentrating hormone, neuropeptide $\mathrm{Y}$, and anorectic neuropeptides in the rat hypothalamus. Diabetes, v.47, p.1687-1692, 1998.

Uchida, Y. et al. Estrogen modulates central and peripheral responses to cold in female rats. The Journal of Physiological Sciences, 2009.

Uchoa, E. T.; Sabino, H. A. C.; Ruginsk, S. G.; Antunes-Rodrigues, J.; Elias, L. L. K. Hypophagia induced by glucocorticoid deficiency is associated with an increased activation of satiety-related responses. Journal of Applied Physiology, v. 106, p. $596-604,2009$. 
Uchoa, E. T.; da Silva, L. E. C. M.; de Castro, M.; Antunes-Rodrigues, J.; Elias, L. L. K. Corticotrophin-releasing factor mediates hypophagia after adrenalectomy, increasing meal-related satiety responses. Hormones and Behavior, v. 58, p. $714-$ 719, 2010.

Uehara, Y.; Shimizu, H.; Ohtani, K-I.; Sato, N.; Mori, M. Hypothalamic corticotropinreleasing hormone is a mediator of the anorexigenic effect of leptin. Diabetes, v. 47, p. $890-893,1998$.

Valle, A.; Santandreu, F. M.; García-Palmer, F. J.; Roca, P.; Oliver, J. The Serum Levels of $17 \beta$-estradiol, Progesterone and Triiodothyronine Correlate with Brown Adipose Tissue Thermogenic Parameters During Aging. Cellular Physiology and Biochemistry, v. 22, p. $337-346,2008$.

Van Marken, W. D.; Vanhommerig, J. W.; Smulders, N. M.; Drossaerts, J. M. A. F. L.; Kemerink, G. J.; Bouvy, N.D.; Schrauwen, P. Teule, G. J. J. Cold-Activated Brown Adipose Tissue in Healthy Men. The New England Journal of Medicine, v. 360, p. $1500-1508,2009$.

Vrang, N. Anatomy of hypothalamic CART neurons. Peptides, v. 27, p. 1970 - 1980, 2006.

Wade, G. N. Gonadal hormones and behavioral regulation of body weight. Physiology \& Behavior, v. 8, p. 523 - 534, 1972.

Wade, G.N. Some effects of ovarian hormones on food intake and body weight in female rats. Journal Comparative Physiology, v. 88, p.183 - 193, 1975.

Wade, G.N.; Zucker, I. Development of hormonal control over food intake and body weight in female rats. Journal Comparative Physiological Psychology, v.70, p.213-220, 1970.

Wang J, Liu R, Hawkins M, Barzilai N, Rossetti L. A nutrient-sensing pathway regulates leptin gene expression in muscle and fat. Nature, n. 393, p. $684-688$, 1998. 
White DW, Tartaglia LA. Leptin and OB-R: body weight regulation by a cytokine receptor. Cytokine Growth Factor Rev, v. 7, p. 303 - 309, 1996.

Wierup, N.; Sundler, F. CART is a novel islet regulatory peptide. Peptides, v. $27, \mathrm{n}$. 8, p. 2031-2036, 2006.

Williams, G., Harrold, J.A., Cutler, D.J. The hypothalamus and the regulation of energy homeostasis: lifting the lid on a black box. Proceedings of Nutrition Society, v. 59, p. 389-396, 2000.

World Health Organization - WHO, Geneva. Obesity: preventing and managing the global epidemic, 2000.

Yan Ng, K.; Yong, J.; Chakraborty, T. R. Estrous cycle in ob/ob and ovariectomized female mice and its relation with estrogen and leptin. Physiology \& Behavior, v. 99, p. $125-130,2010$.

Zhang, Y.; Proenca, R.; Maffei, M.; Barone, M.; Leopold, L.; Friedman, J.M. Positional cloning of the mouse obese gene and its human homologue. Nature, v.372, p.425-432, 1994. 